\title{
Trends in projections of standardized precipitation indices in a future climate in Poland
}

\author{
Marzena Osuch $^{1}$, Renata J. Romanowicz ${ }^{1}$, Deborah Lawrence ${ }^{2}$, and Wai K. Wong ${ }^{2}$ \\ ${ }^{1}$ Institute of Geophysics Polish Academy of Sciences, Warsaw, Poland \\ ${ }^{2}$ Norwegian Water Resources and Energy Directorate, Oslo, Norway \\ Correspondence to: Marzena Osuch (marz@igf.edu.pl)
}

Received: 11 September 2015 - Published in Hydrol. Earth Syst. Sci. Discuss.: 12 October 2015

Revised: 25 March 2016 - Accepted: 26 April 2016 - Published: 13 May 2016

\begin{abstract}
Possible future climate change effects on dryness conditions in Poland are estimated for six climate projections using the standardized precipitation index (SPI). The time series of precipitation represent six different climate model runs under the selected emission scenario for the period 1971-2099. Monthly precipitation values were used to estimate the SPI for multiple timescales $(1,3,6,12$, and 24 months) for a spatial resolution of $25 \mathrm{~km}$ for the whole country. Trends in the SPI were analysed using the MannKendall test with Sen's slope estimator for each grid cell for each climate model projection and aggregation scale, and results obtained for uncorrected precipitation and bias corrected precipitation were compared. Bias correction was achieved using a distribution-based quantile mapping (QM) method in which the climate model precipitation series were adjusted relative to gridded precipitation data for Poland. The results show that the spatial pattern of the trend depends on the climate model, the timescale considered and on the bias correction. The effect of change on the projected trend due to bias correction is small compared to the variability among climate models. We also summarize the mechanisms underlying the influence of bias correction on trends in precipitation and the SPI using a simple example of a linear bias correction procedure. In both cases, the bias correction by QM does not change the direction of changes but can change the slope of trend, and the influence of bias correction on SPI is much reduced. We also have noticed that the results for the same global climate model, driving different regional climate model, are characterized by a similar pattern of changes, although this behaviour is not seen at all timescales and seasons.
\end{abstract}

\section{Introduction}

Drought is an extreme event that can produce significant deleterious effects under both present and future climatic conditions according to the recent Special Report by the Intergovernmental Panel on Climate Change (IPCC) on Managing the Risk of Extreme Events and Disasters to Advance Climate Change Adaptation (SREX).

The assessment of future drought scenarios is crucial for many aspects of the national economy, including agriculture, energy, biodiversity, forestry, and the health and water sectors (Jenkins and Warren, 2015). Therefore, drought can significantly influence the well-being of society and its capacity for resilient development. Recent IPCC reports and scientific articles indicate that drought events have been increasing in frequency and intensity in some regions over the last part of the 20th century as a result of climate change (Kaczmarek et al., 1996; Alexander et al., 2006; Bartholy and Pongracz, 2007; Brázdil et al., 2009; Kiktev et al., 2009; Somorowska, 2009; Dai, 2011; KLIMADA, 2012; Seneviratne et al., 2012). Climate projections suggest that drought is likely to increase (at a medium level of confidence) and may become more intense in some regions, including central Europe (IPCC, 2012), especially in areas with dry conditions in today's climate (IPCC, 2014, AR5). Poland has relatively limited water resources, and in some areas of Poland temporary difficulties in maintaining adequate water supply can occur. Previously published analyses of drought in Poland have mainly been concerned with the classification of drought types and the development of drought indices (Łabędzki, 2007; Łabędzki and KaneckaGeszke, 2009; Tokarczyk, 2013), monitoring of drought conditions (Tokarczyk and Szalińska, 2013; Łabędzki and Bąk, 
2014) and drought hazard assessment for periods when observations are available (Tokarczyk and Szalińska, 2014).

Analysis of the potential impact of climate change on drought in Poland has been addressed by a few other studies at a regional scale. Rimkus et al. (2012) analysed 50year trends (1960-2009) under the recent climate and for drought projections for the future climate (up to 2100) in the Baltic Sea region using the standardized precipitation index (SPI). For the assessment of the observed climatic conditions, gridded precipitation time series at a $1^{\circ}$ resolution from the Climate Research Unit at the University of East Anglia were used. The trend estimated using a MannKendall test indicated an increase in the SPI values for different time averaging periods over most of the studied area, except for Poland, where decreases were found. Future dryness was projected using COSMO Climate Limited-area Model (CCLM) driven by initial and boundary conditions from the global climate model ECHAM5/MPIOM for two emission scenarios (A1B and B1). According to both scenarios, the intensity of drought will likely decline in most of the Baltic Sea area, except in the southern parts, including Poland. Following the A1B scenario, drought occurrence will increase in the summer months in the future in those regions.

The study of the impact of climate change on drought in Poland, carried out within the framework of the project "Development and implementation of a strategic adaptation plan for the sectors and areas vulnerable to climate change" with the acronym KLIMADA (http://www.klimada.mos.gov.pl), indicated that future predictions of annual total precipitation do not show any clear trends (Liszewska et al., 2012). The assessment of trends in seasons shows an increase in winter precipitation (DJF - December, January, and February) of up to $20 \%$ in the eastern part of Poland and a decrease in summer precipitation in south-eastern Poland. In contrast, changes in precipitation in spring and autumn tend to be much smaller (Liszewska et al., 2012). The number of dry days with daily precipitation of less than $1 \mathrm{~mm}$ shows an increasing trend. These changes are more pronounced in eastern and south-eastern Poland (NAS, 2013).

Assessment of the impact of climate change on drought using a climatic water balance (defined as the difference between precipitation and potential evapotranspiration for a given period) for three periods 1971-2000, 2021-2050 and 2071-2100 was carried out by Osuch et al. (2012). The results of the study indicate significant differences between projections derived from the different climate models analysed. A comparison of the median of the ensemble of models in these three periods indicates an increase in water scarcity in Poland. These changes are more pronounced in the southeastern part of Poland.

Another study of drought projections at continental scale was carried out by Bleckinsop and Fowler (2007). In this paper six climate model simulations were analysed following the Special Report on Emission Scenarios (SRES) A2 emission scenario. A considerable model uncertainty due to inter- model variability on regional and local scales was demonstrated. The projections indicate likely decreases in summer and likely increases in winter precipitation. For longer duration droughts, the projections indicate fewer droughts in northern Europe due to larger increases in winter precipitation and more droughts of increasing severity in the south.

Orlowsky and Seneviratne (2013) presented an investigation on future SPI 12 characteristics, again on a continental scale. The results for central Europe showed an increasing trend in median SPI 12.

A new study by Stagge et al. (2015b) presents an analysis of meteorological drought using the most current climate models (23 simulations) for the three projected emission scenarios (RCP2.6, RCP4.5, and RCP8.5) for Europe at a spatial resolution of $0.11^{\circ}(\sim 12.5 \mathrm{~km})$. Meteorological drought was estimated using the SPI at 3-, 6-, and 12-month aggregation periods. In that work the relationship between aggregated precipitation and SPI was developed for the reference period (1971-2000). Then the same transformation was used for future scenarios (2011-2040, 2041-2070, and 2071-2100). The results indicated that precipitation is likely to increase in central and northern Europe; therefore, that area is likely to experience fewer precipitation-based droughts.

Results assessing the influence of climate change on drought in Poland, which are available so far, are limited to either a coarse resolution $\left(1^{\circ}\right)$, few climate models considered (e.g. only one regional climate models (RCM)-GCM combination was used by Rimkus et al., 2012) or to the choice of drought indices, e.g. climatic water balance, that are not suitable for adaptation purposes due to its simplified form with unlimited losses related directly to air temperature increase without limits (i.e. water availability). Three types of drought can be distinguished: meteorological drought, which is evaluated on the basis of precipitation deficit, agricultural drought reflecting a soil moisture deficit, and hydrological drought resulting in a streamflow, groundwater, or reservoir deficit. A meteorological drought often initiates agricultural and hydrological drought but other factors also have an effect on the occurrence and development of agricultural and hydrological drought. The term "drought" has different meanings, depending on the end-user involved. For the description, monitoring and quantification of drought, several indices are used in research and in practice. A detailed review of these indices is presented in Dai (2011). In this article we focus on the description of the degree of meteorological dryness using the SPI developed by McKee et al. (1993). A description of this index is presented in the following section. Dryness, followed in this paper, reflects a wider range of conditions than drought as it describes a state of precipitation deficit in the range from normal conditions down to an extreme drought (Fischer et al., 2013).

Projections of dryness/wetness conditions under a future climate are carried out using simulated climate data obtained from RCM, which are run based on boundary conditions derived from GCM. These models simulate the best-available 
approximation of future climate conditions, although there remains uncertainty related to our insufficient knowledge of physical laws governing the atmosphere and the environment, differences in techniques for coupling RCM and GCM models, as well as assumptions related to global and regional economic and demographic development as represented by a given SRES greenhouse gas emission scenario.

Comparison of the simulations with observations indicates that climate models are able to simulate important aspects of current climate including many patterns of climate variability across a range of scales, for example annual patterns of air temperatures and storm tracks (Ehret et al., 2012; IPCC, 2014, AR5). In particular, models lead to the same or similar tendencies in changes at large spatial and temporal aggregation scales (Ehret et al., 2012). The reliability of such simulations is, however, not proven for all climatic variables. Simulations of precipitation fields are highly biased due to the variety of complex processes leading to precipitation generation in the atmosphere, which includes microphysics of clouds, convection processes, processes in the planetary boundary layer, and the interactions between the ground surface and the atmosphere. Errors occurring in simulated precipitation fields are due to necessary simplifications in the description of these processes in climate models. This problem is well known and reported by many authors (Piani et al., 2010; Hagemann et al., 2011; Liszewska et al., 2012; Osuch et al., 2012; Madsen et al., 2014; Sunyer et al., 2015; Vormoor et al., 2015). Therefore, most studies considering the impact of climate change on processes related to precipitation use statistical downscaling and/or bias correction of the climate simulations relative to observations, rather than basing such analyses on raw (uncorrected) climate model outputs (Madsen et al., 2014).

An application of a bias correction significantly improves the simulations in the control time period, but at the same time, it changes a relationship between climate variables and can violate conservation principles (Ehret et al., 2012). Consistency between the spatio-temporal fields of a climate variable can also be altered. Other problems, which potentially undermine a reliable interpretation of the results of projections, include neglected feedback mechanisms and an assumption of stationarity of bias correction method parameters derived for a period with available observations but later used for changed conditions during future periods. Application of bias correction in the modelling chain can alter climate change signals (Hagemann et al., 2011; Cloke et al., 2013; Gutjahr and Heinemann, 2013; Teng et al., 2015). The ongoing discussion on the suitability of bias correction of data derived from climate model simulations was initiated by Christiansen et al. (2008) and has been taken further by Ehret et al. (2012), Muerth et al. (2013), and Teutschbein and Seibert (2013), among others. Proposed solutions to this problem include presenting results for both bias corrected and non-corrected inputs and analysis of the worst case scenario. The best, but also the most challenging, solution could

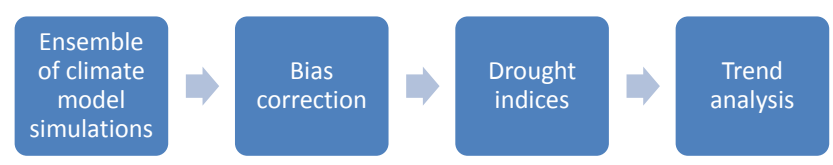

Figure 1. A scheme of the applied modelling chain.

be achieved by the improvement of climate models (Ehret et al., 2012) such that bias correction is not required.

The aim of this paper is an estimation of potential local changes in the degree of dryness in Poland resulting from future climate change, as interpreted from changes in the estimated SPI. We apply an ensemble of six GCM-RCM models in order to consider some of the uncertainty introduced by differences between climate model projections. The influence of bias correction on the resulting projections of trends in the SPI values is also analysed. Such work has not been previously undertaken for the whole of Poland, but is a necessary input for developing climate change adaptation policies related to the projected degree of meteorological dryness.

The article is organized as follows. In Sect. 2 we describe the methodologies used to develop precipitation and SPI projections for Poland. In Sect. 3 a comparison of the simulated and observed precipitation time series is presented, together with the estimated tendencies in spatio-temporal changes in drought condition in Poland over the period 1971-2099. The last section presents a discussion and summarizes the most important results of the study.

\section{Methods}

The chain of analysis underlying the estimation of changes in drought indices is illustrated in Fig. 1. For these analyses, a multi-model ensemble of climate projections has been used in keeping with recommendations for such work (e.g. van der Linden and Mitchell, 2009; Knutti et al., 2010). Precipitation time series generated by the climate models have been bias corrected relative to observations and further details are given below. On the basis of the corrected precipitation series from the climate projections, the meteorological dryness indices have been calculated. Tendencies in changes are estimated using non-parametric trend analysis (Kundzewicz and Robson, 2004). For the assessment of the influence of the bias correction method on the temporal variability of the meteorological dryness, the analyses are carried out for both uncorrected and bias corrected precipitation time series from the climate models.

\subsection{Climate data}

Climate variables have been obtained from the EU FP6 ENSEMBLES project (van der Linden and Mitchell, 2009), in the form of time series of precipitation derived from six different RCM-GCMs: DMI HIRHAM5 ARPEGE, SMHIRCA 
BCM, RM51 ARPEGE, MPI M REMO ECHAM5, KNMI RACMO2 ECHAM5 r3, and DMI HIRHAM5 BCM following A1B climate change scenario for the time period: 19712100. The A1B emission scenario belongs to the SRES family described in the IPCC SRES (Nakicenowic et al., 2000) and used to make projections for the IPCC Third Assessment Report (TAR) and in the IPCC Fourth Assessment Report (AR4). These six simulations are based on five RCMs (DMI HIRHAM5, SMHIRCA, RM51, MPI M REMO, and KNMI RACMO2) driven by three different GCMs (ARPEGE, ECHAM5, and BCM). In two cases, the same RCM was used with different GCMs (ARPEGE and BCM). These combinations of RCM-GCM simulations are shown in Table 1. In this work we applied simulations of climate models transformed to normal grids (non-rotated) with a spatial resolution of $0.25^{\circ} \times 0.25^{\circ}$. The analyses were carried out for two periods: a reference period 1971-2000 and the entire available period 1971-2099.

The simulations in the reference period (1971-2000) were compared with observations from synoptic stations (point measurements) and also with the latest available version of a European daily high-resolution gridded data set (E-OBS version 10) from the European Climate Assessment and Data set (ECA \& D; Haylock et al., 2008) of the Royal Netherlands Meteorological Institute (KNMI). The spatial resolution of the E-OBS grid cells is the same as the ENSEMBLES RCM domain (i.e. $0.25^{\circ} \times 0.25^{\circ}$ ).

\subsection{Bias correction}

Our previous analyses (Liszewska, et al., 2012; Osuch et al., 2012) indicated that raw climate simulations, especially for precipitation time series, are highly biased. Following the papers of Ehret et al. (2012) and Sunyer et al. (2015) we included an additional post-processing step, i.e. bias correction of climatic variables, which is a standard procedure for climate change impact studies. In this work we used a distribution-based quantile mapping (QM) method (Piani et al., 2010) applied to daily values subsampled on a monthly basis to correct biases in the precipitation time series derived from the climate models. The correction was done relative to E-OBS reanalysis precipitation data (Haylock et al., 2008), as this data set provides the best estimate of grid box averages and has the same resolution as the outputs from the climate models considered. Quantile mapping methods have a number of advantages over methods that only correct the mean and variance (Sunyer et al., 2015) and have been used in numerous previous studies, e.g. Dosio and Paruolo (2011) and Gudmundsson et al. (2012). The QM method is based on the assumption that a transformation $(h)$ exists such that the distribution of quantiles describing the simulated time series of precipitation $\left(P^{\mathrm{RCM}}\right)$ can be mapped onto the quantile distribution of the observations $\left(P^{\text {obs }}\right)$ :

$$
P^{\mathrm{Obs}}=h\left(P^{\mathrm{RCM}}\right) .
$$

Table 1. GCM and RCM combinations used from ENSEMBLES project. The number denotes number of simulations.

\begin{tabular}{lcccc}
\hline GCM-RCM & ARPEGE & ECHAM5 & BCM & $\begin{array}{c}\text { Total } \\
\text { scenarios }\end{array}$ \\
\hline DMI HIRHAM5 & 1 & 0 & 1 & 2 \\
SMHIRCA & 0 & 0 & 1 & 1 \\
RM51 & 1 & 0 & 0 & 1 \\
MPI M REMO & 0 & 1 & 0 & 1 \\
KNMI RACMO2 & 0 & 1 & 0 & 1 \\
\hline Total scenarios & 2 & 2 & 2 & 6 \\
\hline
\end{tabular}

In the application of this method here, observed and simulated time series were fitted to a gamma distribution. The distribution parameters were estimated using the maximum likelihood method. Only wet days $\left(P>0.0 \mathrm{~mm} \mathrm{day}^{-1}\right)$ were included in this analysis. The inverse of the derived gamma distribution for observed time series is used to correct the quantiles of simulations, following the transformation:

$\hat{P}_{\text {corr }}^{\mathrm{RCM}}=F_{\text {Obs }}^{-1}\left(F_{\mathrm{RCM}}\left(P^{\mathrm{RCM}}\right)\right)$

where $F_{\mathrm{Obs}}$ denotes the cumulative distribution function (cdf) of observations and $F_{\mathrm{RCM}}$ is the cdf of simulated values.

The relationship (Eq. 2) between quantile-corrected and simulated data was parametrized using the power transformation:

$\hat{P}_{\text {corr }}^{\mathrm{RCM}}=\left\{\begin{array}{cll}b\left(P^{\mathrm{RCM}}-x_{0}\right)^{c} & \text { for } & P^{\mathrm{RCM}} \geq x_{0} \\ 0 & \text { for } & P^{\mathrm{RCM}}<x_{0}\end{array}\right.$,

where coefficients $b$ and $c$ are calibrated for the best fit, $x_{0}$ is estimated threshold value of precipitation below which modelled precipitation is set to zero.

In addition to the correction of precipitation values, the number of wet days is also corrected based on the empirical probability of non-zero values in the observations. This is a necessary part of the bias correction, as RCMs tend to simulate too many wet days with low values of precipitation. All values for precipitation below this threshold $\left(x_{0}\right)$ are set to zero for the simulated data. The transformation $h$ and the wet day correction derived for the control period are further applied in the correction of precipitation data for future periods. The correction parameters are evaluated for every grid and every month separately.

\subsection{Standardized precipitation index}

Many different indicators of meteorological drought can be found in the literature (Mishra and Singh, 2010), although the SPI is one of the most widely applied. The index is used for both research and operational purposes in over 60 countries (e.g. Bordi et al., 2009; Moreira et al., 2012; Sienz et al., 2012; Gocic and Trajkovic, 2013; Liu et al., 2013; Dutra 
et al., 2014; Zargar et al., 2014; Jenkins and Warren, 2015; Swain and Hayhoe, 2015; Zarch et al., 2015).

SPI has been developed by McKee et al. (1993). It is a relatively simple index based only on precipitation and quantifies a precipitation deficit for a sequence of data (Hayes et al., 1999; Seiler et al., 2002). Time series of precipitation for a particular location are fitted to the gamma distribution, following the recommendation by Stagge et al. (2015a). SPI values are then estimated by a transformation of the cumulative probability to a standard normal variable with a zero mean and a variance equal to 1 . Negative values of SPI indicate lower than median precipitation, whilst positive values denote higher than median precipitation. The calculated values of SPI give estimates of the degree of dryness for a given period and location. Different thresholds of SPI value are established to distinguish a meteorological drought. Originally McKee et al. (1993) proposed a threshold SPI = 0, although a later assessment by Agnew (2000) and Łabędzki (2007) suggested that drought conditions start at SPI $=-1$. Due to the standardization of variables, SPI values can be used to represent wetter and drier areas in a comparable way.

The SPI can be used to quantify the precipitation deficit at multiple timescales (1, 3, 6, 12, 24 months). These timescales reflect the impact of drought on the short-term water supplies, which are important for agriculture, as well as on systems that may have more storage and, therefore, a longer response time such as water resources in the form of streamflow, reservoir storage, and groundwater supplies.

In the assessment of a meteorological dryness using the SPI index, the length of the precipitation series and the probability distribution describing data are very important (Mishra and Singh, 2010). Wu et al. (2005) recommended the use of the longest possible period for the derivation of the SPI, as short data sets could result in large errors of estimated values. For the comparison of indices between different locations, the choice of the same period is suggested. Following that recommendation, the aggregated precipitation totals from the entire period (1971-2099) were normalized. The analysis of SPI values based on the entire time series presents an opportunity to estimate the tendency of changes in the SPI time series, which was one of the major aims of this work. However, for the purpose of adaptation to climate change, the reference period to which the changes are related plays an important role. Namely, when the whole period is taken for the normalization, normal conditions refer to the year 2035, which in the case of non-stationarity may lead to some difficulties in interpreting the results, as it changes the analyst's perspective.

In an alternative approach presented by Stagge et al. (2015b) a non-linear transformation (normalization) is developed for the present period (for example 1971-2000) and that transformation is further applied to future climate conditions. That approach also has some drawbacks. Future climate conditions could be different than those observed; therefore an application of a relationship based on present conditions could lead to extrapolation outside the range of observed values. The second problem with the alternative approach is related to shorter time series that could result in errors in the fitting of the distribution and the normalization of the aggregated time series. This problem is mentioned in the work of Wu et al. (2007).

In this work the gamma distribution was chosen for description of the precipitation time series following the recommendation of McKee et al. (1993), Lloyd-Hughes and Saunders (2002) and analyses of suitable statistical tests (Anderson-Darling, chi-square and Lilliefors). The distribution parameters were estimated using the maximum likelihood method. For locations where no precipitation occurs in the time series for a given period over analysed aggregation timescale, the cumulative probability $H(x)$ is calculated from the following equation

$H(x)=\left\{\begin{array}{ccc}q & \text { if } & x=0 \\ q+(1-q) G(x) & \text { if } & x>0\end{array}\right.$

where $q$ is the probability of no precipitation for the period estimated from the frequency of observations of zero, and $G(x)$ denotes the cumulative probability derived from gamma distribution.

The SPI is the inverse of the normal cumulative distribution function corresponding to the normalized probability $H(x)$. The influence of dry days on the normality of derived SPI values at different timescales was tested by the Anderson Darling test, where the null hypothesis is that a sample comes from a population described by a normal distribution. The results indicated that the applied test fails to reject the null hypothesis at 0.05 level in all cases. Other methods of normality testing of the SPI values have been applied in other published studies, e.g. the Shapiro-Wilk statistic and absolute value of the median smaller than 0.05 (Wu et al., 2007; Kumar et al., 2009; Stagge et al., 2015a).

\subsection{Trend analysis}

The last element in the applied modelling chain presented in Fig. 1 is the trend analysis of the estimated SPI time series. There are many techniques that can be used to estimate trends in time series, such as linear regression, Spearman's rho test, Mann-Kendall test, seasonal Kendall test, and also the application of time series models (Kundzewicz and Robson, 2004). In this work the modified Mann-Kendall test (Mann, 1945; Kendall, 1975; Hamed and Rao, 1998) was applied to estimate monotonic trends in the SPI time series. In this approach it is assumed that the data are not serially correlated over time. There are no assumptions related to the distribution of residuals as is the case for a linear regression.

The original Mann-Kendall test for trend is based on a rank correlation test for the observed values and their order in time and operates on all possible combinations of points. 

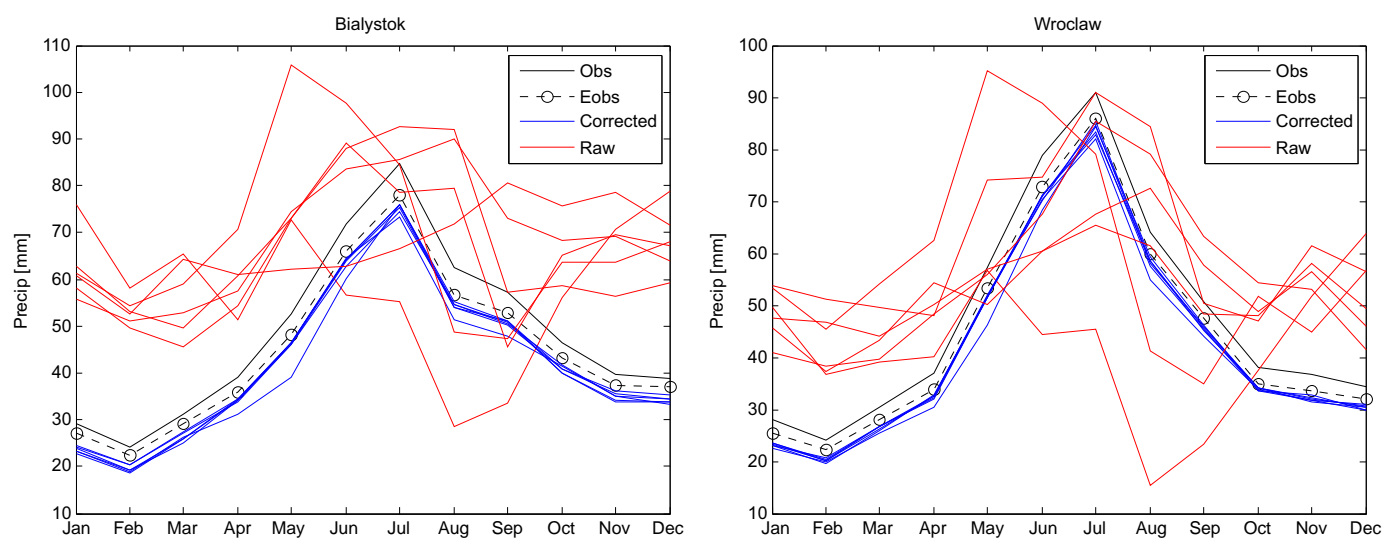

Figure 2. Comparison of mean monthly sums of precipitation calculated over the reference time period for two grid cells located close to Białystok (NE Poland) and Wrocław (SW Poland). Black continuous lines denote observations from meteorological stations, dashed lines denote observations from E-OBS reanalysis grid cells, red lines denote uncorrected precipitation series from the RCMs, and blue lines denote the bias corrected precipitation series.

The Mann-Kendall test statistics $S$ is calculated from the following equation:

$S=\sum_{k=1}^{n-1} \sum_{j=k+1}^{n} \operatorname{sgn}\left(x_{j}-x_{k}\right)=\left\{\begin{array}{ccc}+1 & \text { if } & \left(x_{j}-x_{k}\right)>0 \\ 0 & \text { if } & \left(x_{j}-x_{k}\right)=0, \\ -1 & \text { if } & \left(x_{j}-x_{k}\right)<0\end{array}\right.$

where $n$ is the number of observations. For independent and randomly ordered data for large $n$, the $S$ statistics approximate a normal distribution with mean $E(S)=0$ and a variance equal to $\operatorname{var}(S)=n(n-1)(2 n+5) / 18$.

The significance of a trend is tested by comparing the standardized $Z$ test statistics with the standard normal cumulative distribution at a selected significance level. Positive values of $Z$ statistics indicate a positive trend (an increasing trend) while negative $Z$ values indicate a decreasing trend. The trend is statistically significant at $\alpha=0.05$ level when the absolute value of $Z$ is higher than 1.96.

The application of the Mann-Kendall test can be affected by a serial correlation of data and also by seasonality effects, as discussed by Hamed and Rao (1998). As we perform independent analysis for each month and season, the seasonality effect is eliminated.

To avoid problems with autocorrelation a modified MannKendall test has been developed (Hamed and Rao, 1998). The modification allows the test to be applied to data with serial correlation as is the case of SPI values for longer time steps (12 and 24 months). The modified Mann-Kendall test was used for all aggregation scales $(1,3,6,12$, and 24 months). To account for an effect of a serial correlation the correction ratio $n / n_{\mathrm{S}}^{*}$ is introduced during the calculation of a variance of the $S$ statistics.

$\operatorname{var}^{*}(S)=\operatorname{var}(S) \frac{n}{n_{\mathrm{S}}^{*}}$,

$$
\begin{gathered}
\frac{n}{n_{\mathrm{S}}^{*}}=1+\frac{2}{n(n-1)(n-2)} \sum_{i=1}^{n-1}(n-i) \\
(n-i-1)(n-i-2) \rho_{\mathrm{S}}(i),
\end{gathered}
$$

where $\rho_{\mathrm{S}}$ is the autocorrelation function.

The slope of trend can be estimated using the Sen's method where the trend is assumed to be linear (Wilcox, 2005). Following that method, the slopes between all data pairs are calculated and then the overall slope is estimated using the median of these slopes. The median value is used such that the results are not strongly affected by outliers.

\section{Results}

\subsection{Comparison of simulated and observed data for the reference period}

\subsubsection{Seasonal pattern of precipitation}

In the first step of analysis, a comparison of observed and simulated (both uncorrected and bias corrected) average monthly precipitation for the reference period (19712000 ) was performed. The results in the form of annual runs for two grid cells located close to Białystok (NE (northeastern) Poland) and Wrocław (SW (south-western) Poland) are presented in Fig. 2. It can be seen that uncorrected RCM precipitation values (shown as red lines) overestimate the observations (black lines) and the observed seasonal pattern is not reproduced. For the uncorrected data, significant differences between the RCM-GCM combinations are evident especially during the summer months. Application of bias correction leads to an improvement relative to observed values. The bias corrected precipitation values are characterized by a similar seasonal pattern to that of the observed values, with a slight underestimation of monthly precipitation values relative to observed values. This is partly due to the fact that bias 

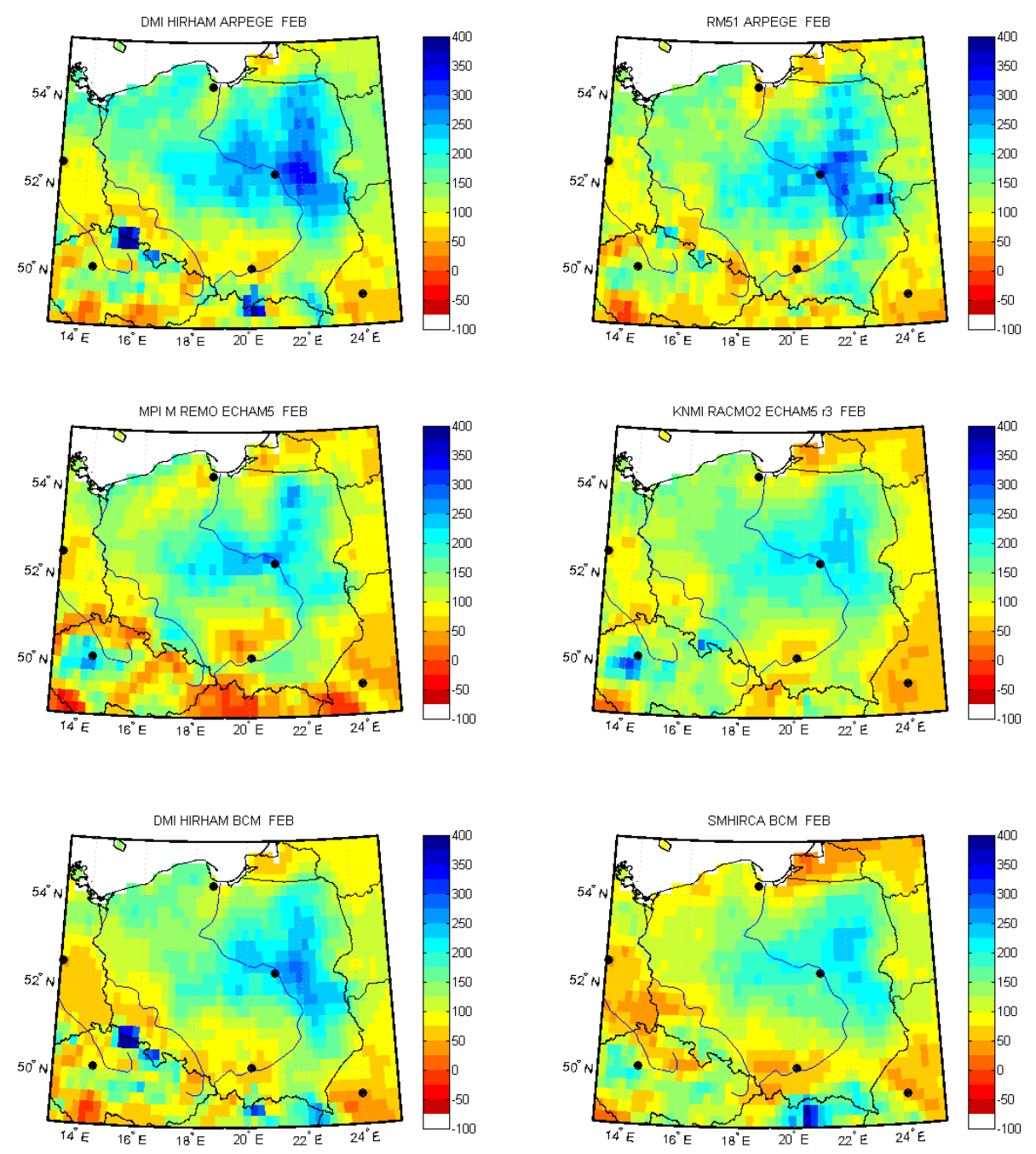

Figure 3. Comparison of spatial patterns of relative differences [\%] in the average monthly precipitation in February between uncorrected and bias corrected data for the reference period 1971-2000.

correction was undertaken using E-OBS data rather than station data. However, in addition, it must be remembered that bias correction is performed on individual daily precipitation values, rather than monthly totals. In addition, a gamma distribution is used as an approximation to the empirical distribution of values. Therefore, some differences in the final results are to be expected.

A comparison of the spatial patterns of the difference between average monthly precipitation based on uncorrected and bias corrected RCM data was performed, and an example for the month of February is shown in Fig. 3. Red indicates negative and small positive differences between uncorrected and the bias corrected values, whilst blue indicates large differences $(>200 \%)$ after bias correction. Similarities between the climate models can be observed, and in all cases, the largest differences are found in the eastern and north-eastern regions of Poland. Figure 3 also suggests that the highest precipitation intensities are simulated by RCMs driven by the ARPEGE GCM, as the largest relative discrepancies shown in the figure are associated with that model.

The pattern of differences between corrected and uncorrected values for monthly precipitation varies between months. A comparison of the spatial pattern of residuals for July is presented in Fig. S1 (Supplement). Generally, the differences for July are smaller than in winter months. In the case of summer months the RCM results are not consistent, and significant differences in direction of changes and intensities are apparent.

In addition to the comparison of mean monthly values, the variability in the monthly precipitation during the reference period was also analysed. The results of that comparison for two grid cells located in the NE and SW Poland are presented in Fig. 4. The results indicate similar tendencies in observed and simulated data, with higher variability in monthly values for precipitation during summer months and lower variability during winter months. Uncorrected RCM data overestimate 

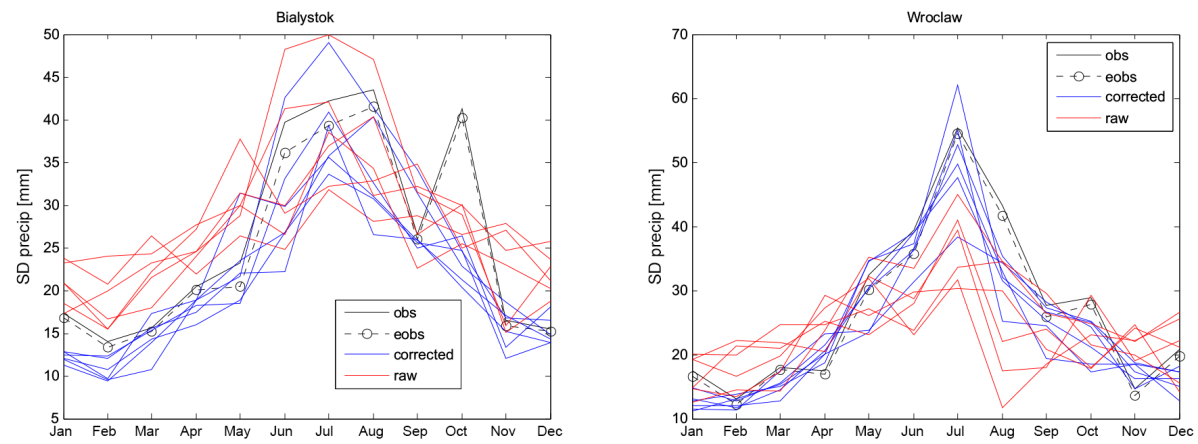

Figure 4. Comparison of standard deviation of monthly sum of precipitation calculated over the reference time period for two grid cells located close to Białystok (NE Poland) and Wrocław (SW Poland). The black continuous line denotes observations from meteorological stations, black dashed lines denote observations from the E-OBS reanalysis, red lines denote precipitation values from uncorrected RCMs, and blue lines denote bias corrected RCM precipitation data.

the variability in monthly precipitation in the winter months and underestimate it in the summer period for most of models, relative to both observed stations and E-OBS data. Corrected data are characterized by similar variability throughout the year to the observed data sets.

A comparison of the spatial pattern of differences in the standard deviation of monthly precipitation is shown in Fig. 5 for the month of February. The outcomes indicate a similar pattern of differences between the climate models, although the intensities vary between the models. The pattern is similar to those obtained for differences in mean value with the highest differences in eastern and north-eastern regions of Poland. The uncorrected ARPEGE model simulations again show the largest discrepancies relative to observed values, as indicated by large differences between uncorrected and corrected data.

\subsubsection{Number of wet days}

The number of wet days can be important for the estimation of meteorological drought. Figure 6 shows a comparison of the observed (E-OBS data and point measurements at meteorological stations) and the simulated mean monthly number of wet days for two grid cells located close to Białystok (NE Poland) and Wrocław (SW Poland). The number of wet days simulated by climate models is significantly different from observations, both for annual and seasonal totals. Almost all uncorrected RCM simulations overestimate the number of days with precipitation relative to observations. The largest differences are associated with the RM51 ARPEGE climate model for the month of May for both locations. The DMI HIRHAM5 ARPEGE model gives a very low number of wet days in July, August, and September. The bias corrected simulations reveal the observed annual of mean monthly number of wet days.

Figure 6 illustrates the dependence of the simulation results on the minimum rainfall threshold. The upper diagrams, which illustrate all of the days with precipitation, show that most of the models simulate continuous rain of varying intensity. Introducing a threshold of $1 \mathrm{~mm}$ (lower row in Fig. 6) changes the seasonal pattern and makes it more comparable with the observed number of wet days.

The derived pattern of direction and intensity of local corrections for corrected and raw number of wet days is very similar to the seasonal pattern sum of precipitation presented in the previous section.

\subsection{Future changes}

Following the methodology presented in the previous section, SPI indices were calculated on the basis of simulated precipitation time series from the period 1971-2099. The analysis was carried out for

- each grid cell $(49 \times 26)$ excluding 108 grid cells over the Baltic Sea;

- each climate model (6 models);

- 1-month (SPI 1), 3-month (SPI 3), 6-month (SPI 6), 12month (SPI 12), and 24-month (SP 24) timescales.

An example of the SPI 12 time series for raw climate data for one grid cell located close to Białystok (NE Poland) is shown in Fig. 7. It is seen that the results depend on the climate model considered and that for all models there is a high degree of interannual variability.

In order to examine the influence of bias correction on the meteorological dryness projections, the Mann-Kendall test for trend was applied and the slope of the SPI trend was estimated using Sen's method for raw and corrected precipitation data.

\subsubsection{SPI 1}

The results of trend analysis for the SPI 1 for one grid cell located in the NE Poland close to Białystok are presented in Table 2. This selection was made on the basis of the results 

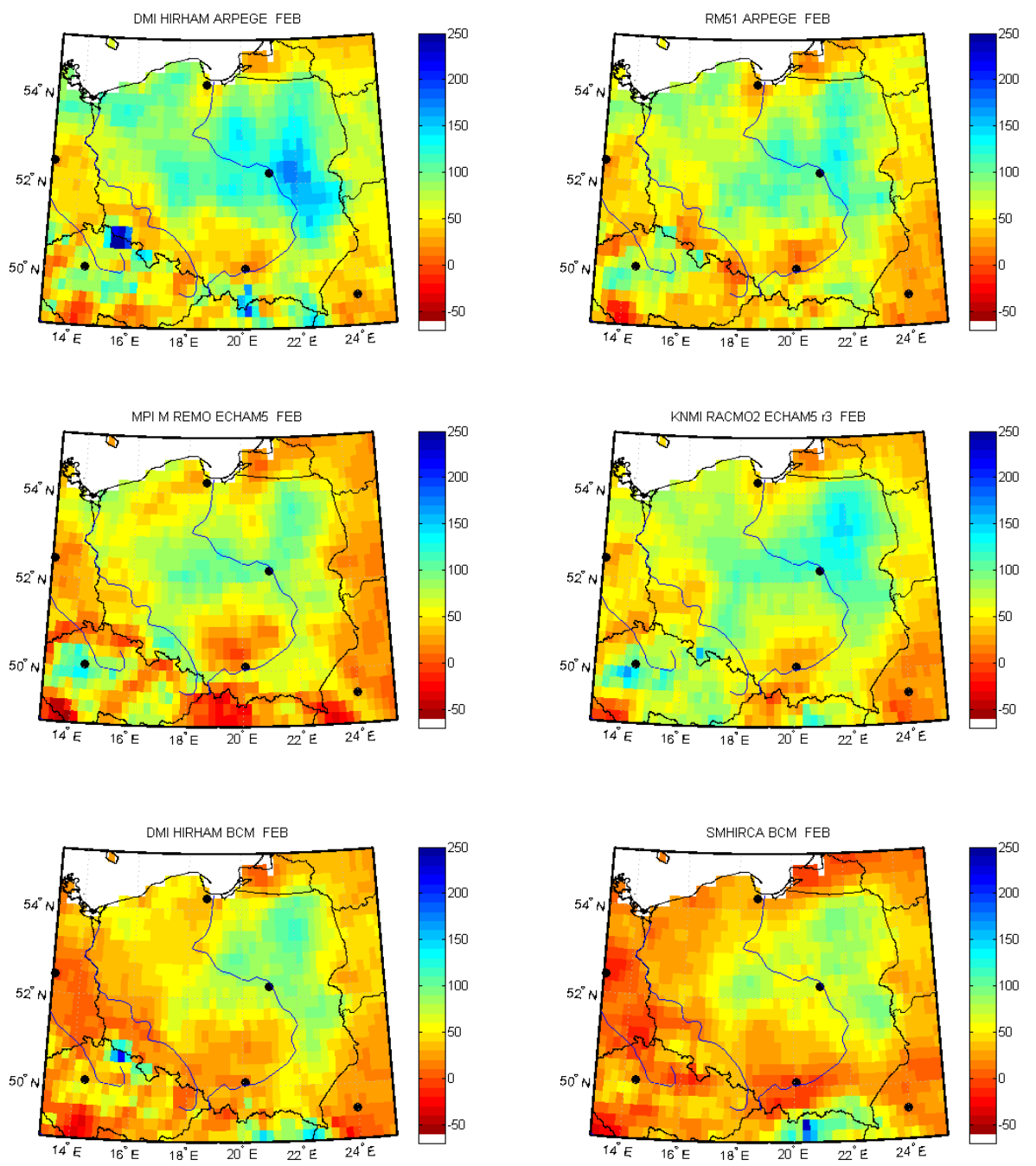

Figure 5. Comparison of spatial patterns of differences in the standard deviation of monthly precipitation for February for uncorrected relative to corrected RCM data for the month of February for the reference period 1971-2000.

of Liszewska et al. (2012). The largest changes in winter precipitation are projected to be in that area. On the left side of the table outcomes of the analysis for the bias corrected data are shown, whilst on the right side the trends for raw data are presented. It is clear that the sign of the estimated trends depends on the month, climate model, and whether or not the data are bias corrected. The results for uncorrected data in February, May, October, and November lack statistically significant trends. In those cases the results are consistent between models. In the other months there is no consistency between models with respect to the estimated trends. According to the estimated trends, the RCM-GCM models can be classified into wet vs. dry models. "Dry" models (e.g. ARPEGE GCM) project a decrease in SPI values in the summer period and no statistically significant changes in winter. The opposite is true for the "wet" models (ECHAM5 and BCM), for which an increase in SPI 1 values is projected in January and December with no statistically significant trend in summer.
The application of bias correction slightly alters the results of the trend analyses. In this case, the DMI HIRHAM ARPEGEs project a decrease of the SPI 1 values in April and August using uncorrected data but does not for bias corrected data. The trends in SPI 1 in February for two climate models are statistically significant for corrected data. The results for other months are consistent for uncorrected and bias corrected data.

The results represent one grid cell point located in northeastern Poland. The same analyses were carried out for all grid cells in the analysed domain. The slopes of the estimated trends for the SPI 1 for the time series for January are shown in Fig. 8. It is seen that for the uncorrected data, the estimated slope of SPI 1 (January) in the period 1971-2099 strongly depends on the climate model and the region within Poland. For the ARPEGE GCM, there is no statistically significant trend across the whole of Poland. The outcomes from other models indicate an increase in the SPI 1 values (indicating 

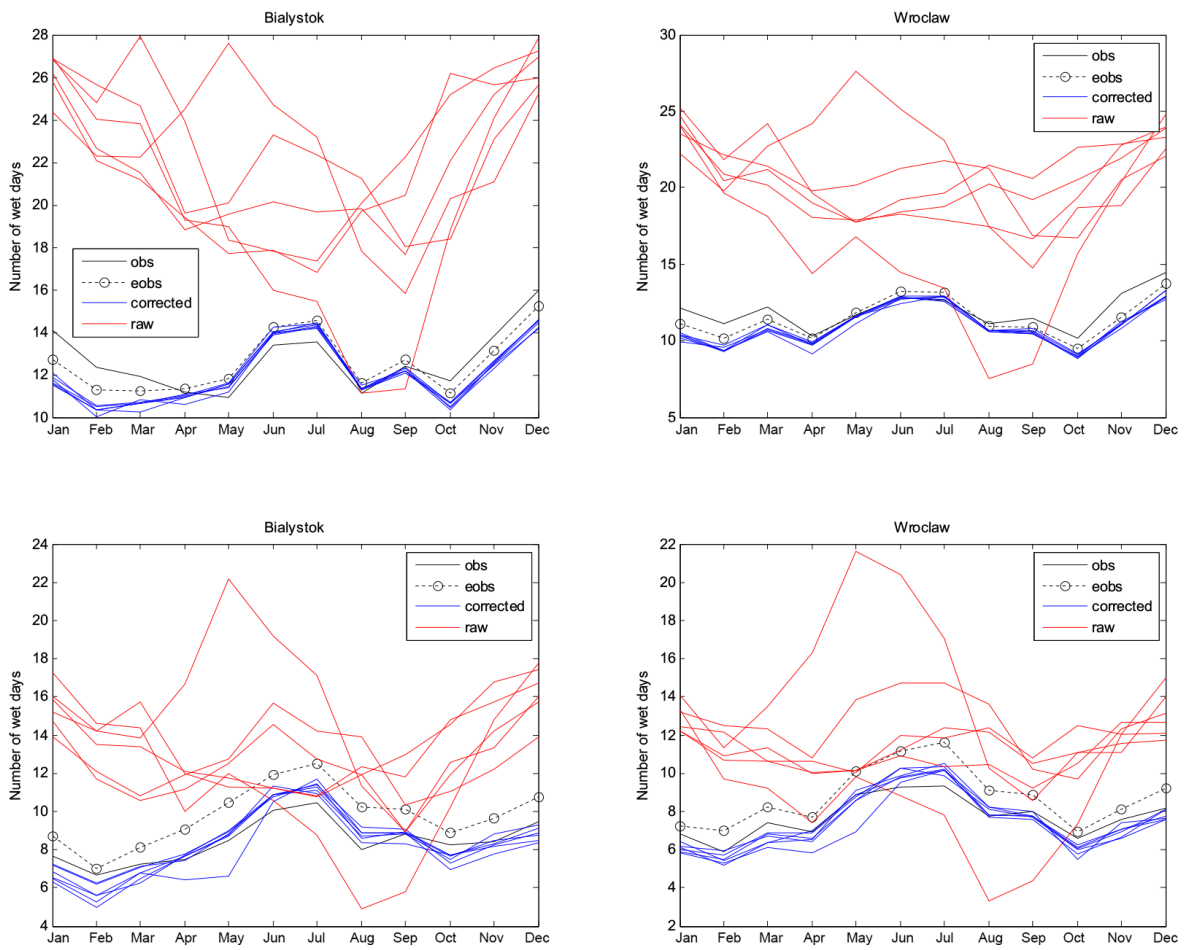

Figure 6. Comparison of mean monthly number of wet days with the minimum rain threshold values set to $0.1 \mathrm{~mm}$ (upper panels) and $1 \mathrm{~mm}$ (lower panels) for the uncorrected RCM data (raw), calculated over the reference time period for two grid cells located close to Białystok (NE Poland) and Wrocław (SW Poland). The black continuous line denotes observations from the meteorological stations, black dashed lines denote observations from the E-OBS reanalysis, red lines denote uncorrected precipitation values from the RCMs, and blue lines denote corrected RCM precipitation values.
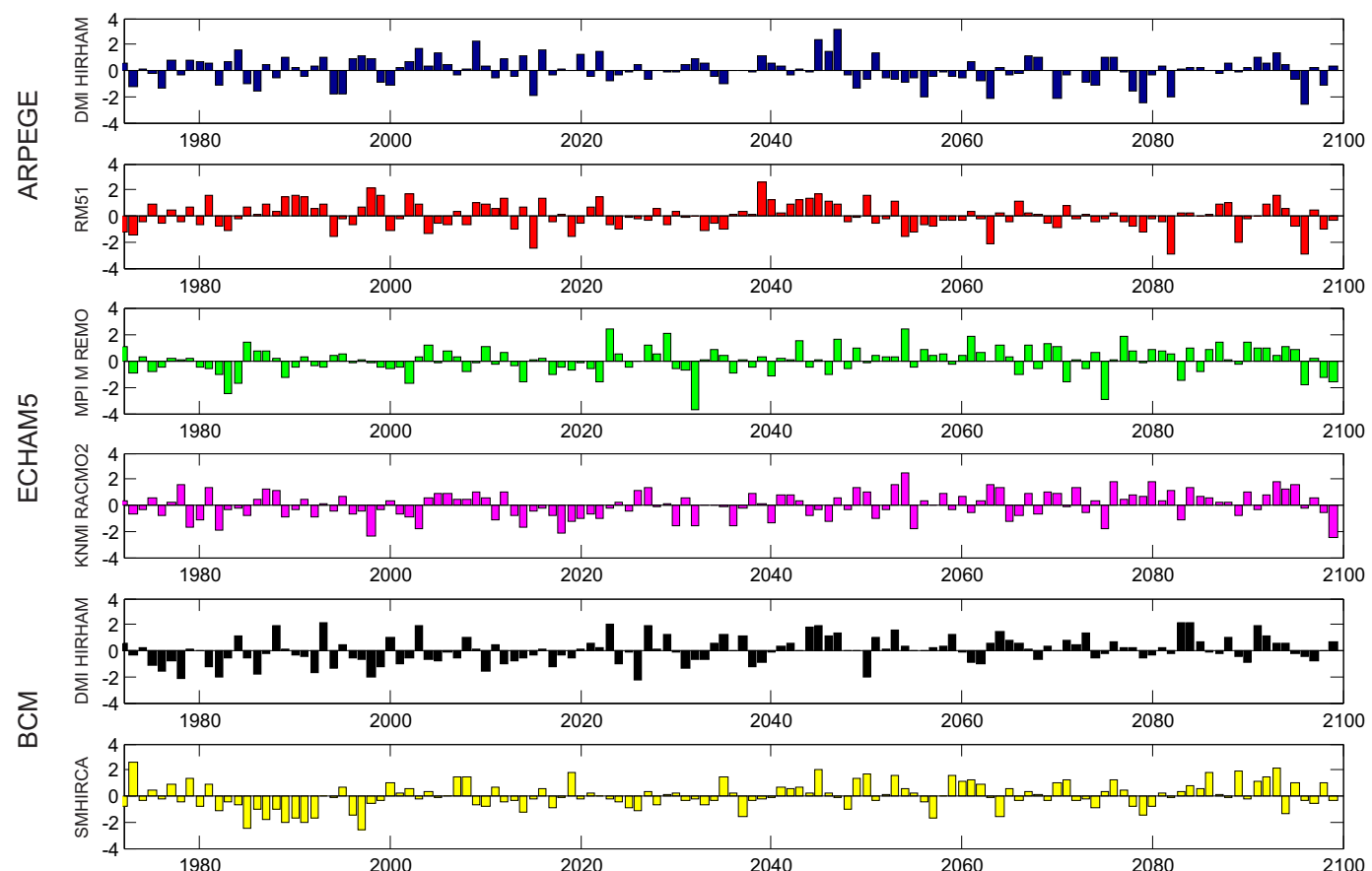

Figure 7. An example of SPI 12 time series for raw data: DMI HIRHAM ARPEGE, RM51 ARPEGE, MPI M REMO ECHAM5, KNMI RACMO2 ECHAM5 r3, DMI HIRHAM BCM, SMHIRCA BCM. 

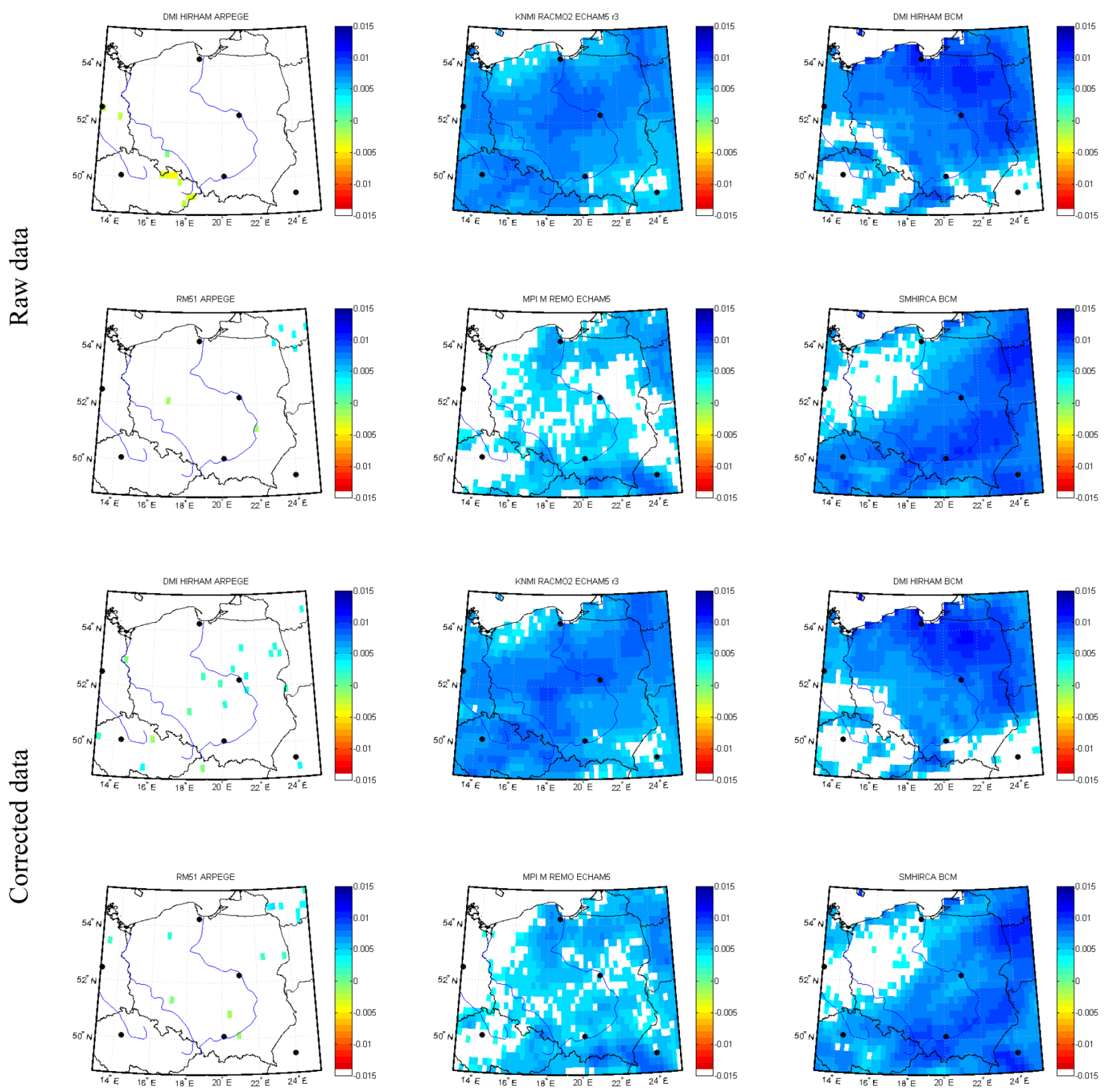

Figure 8. The results of the Mann-Kendall trend analysis for SPI 1 for January. The colour scale denotes the slope of the estimated trend. White colour indicates a lack of a statistically significant trend.

wetter conditions), but the magnitude of the changes (as indicated by the slope of the trend) and the location of areas with or without statistically significant trends are not consistent. The application of the bias correction procedure slightly changes the results. In this case, the tendency of changes is similar as for uncorrected data (no trend for ARPEGE model and an increase in SPI values for BCM and ECHAM5 models). The magnitude of the changes varies between models, but in some cases it is slightly larger than for the corrected data.

A comparison of statistically significant trends in the SPI 1 for July is presented in Fig. 9. There are significant differences between climate models. Trend results based on the ARPEGE climate model are characterized by a decrease in the SPI 1 values for the whole of Poland. The ECHAM5 climate model projects a decrease in SPI 1 in the south-eastern part of Poland but no statistically significant changes in the 

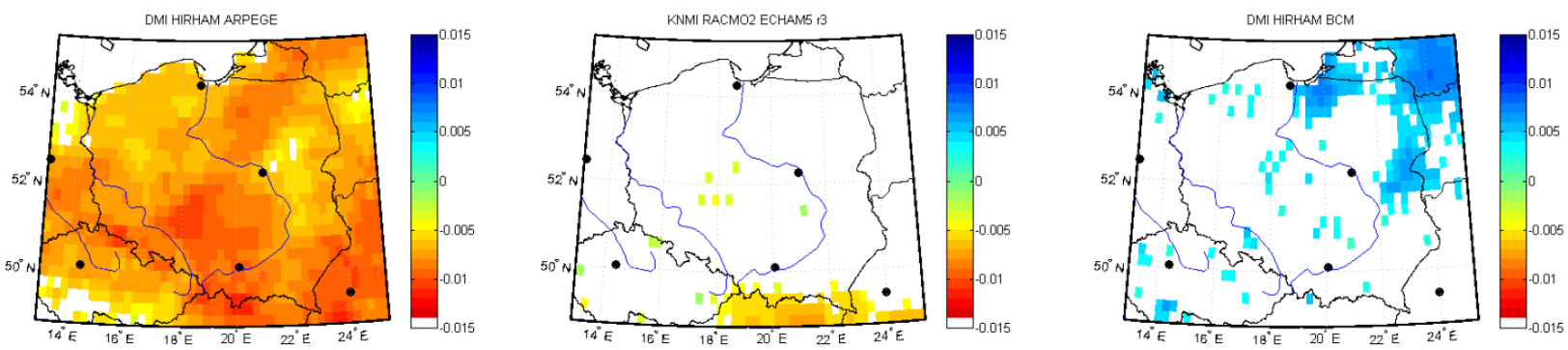

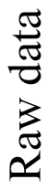
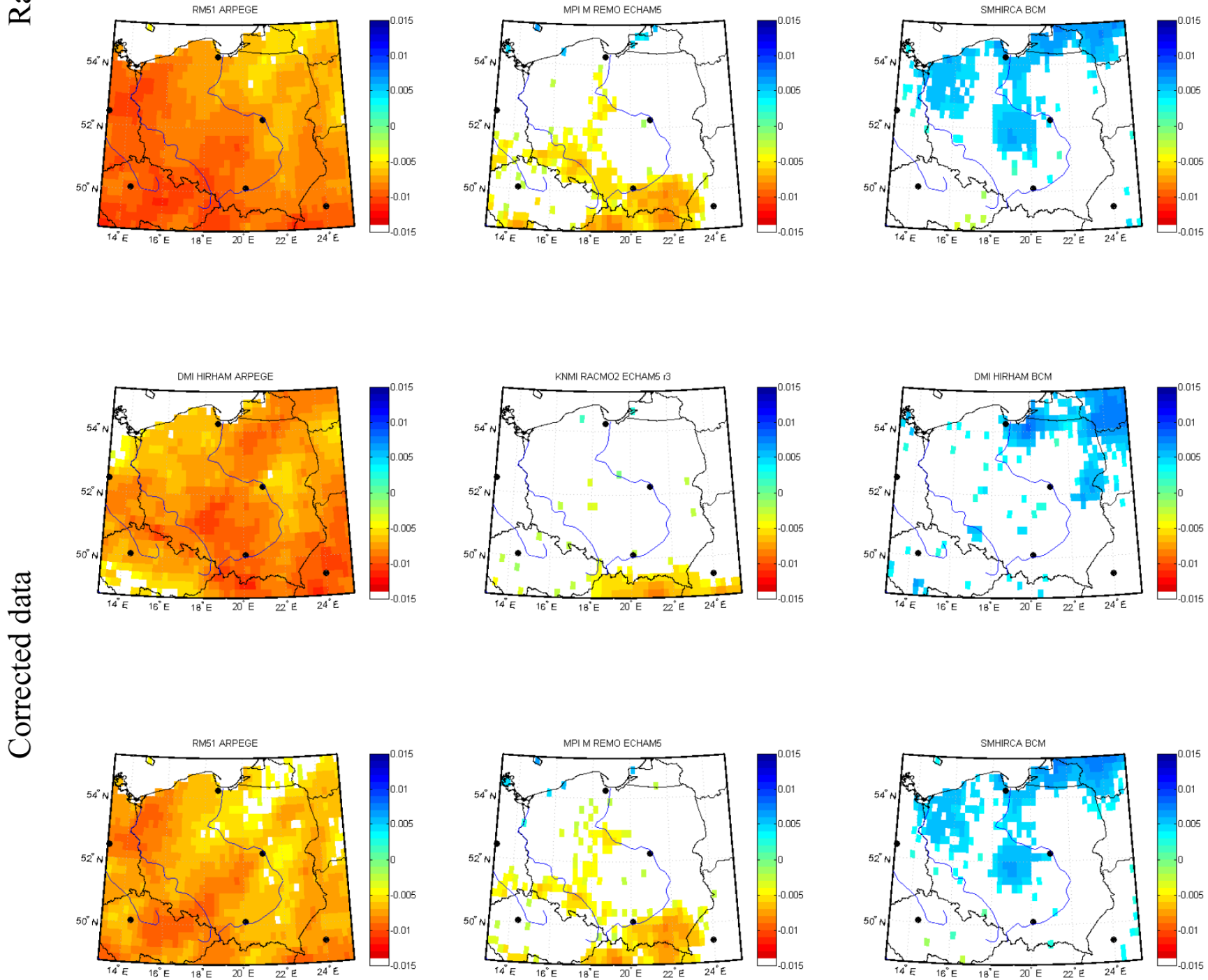

Figure 9. Results of the modified Mann-Kendall test for SPI 1 for July. Colour scale denotes the slope of the estimated trend. White areas indicate a lack of a statistically significant trend. 


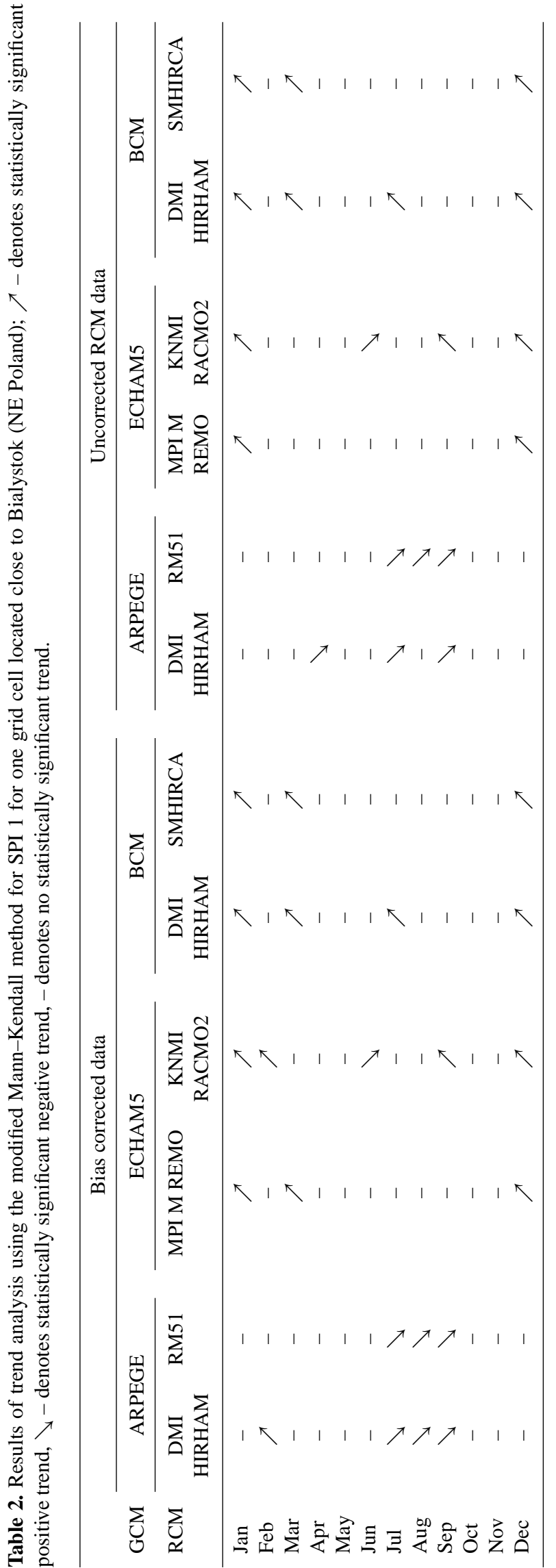

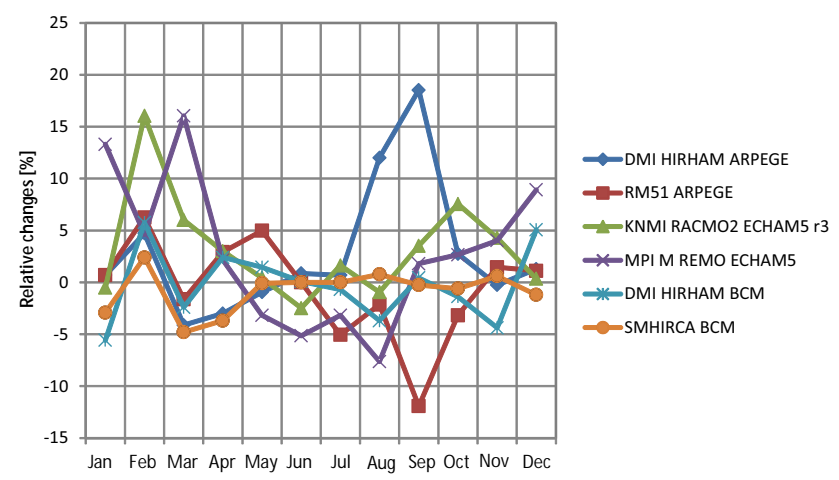

Figure 10. The differences in the percentage of grid cells with a statistically significant trend for data with and without bias correction.

rest of the country. A different tendency is seen for the trend analysis based on the BCM climate model; i.e. an increase in the SPI values in the north-eastern and north-western regions of Poland and no change in other areas.

Analyses of the estimated trend for raw and corrected data indicate similar tendency of changes with small differences in trends in the SPI 1 values as a result of the bias correction procedure.

To summarize the influence of the bias correction on the estimated trends of SPI 1 values, a comparison of the number of grid cells with statistically significant trends is presented in the Supplement (Table S1). It is seen that the latter strongly depends on the month, climate model, and to a lesser extent also on whether or not bias correction has been applied. The total area with statistically significant trends for the uncorrected data is the largest for analyses based on the BCM and ECHAM5 climate models for winter months (December, January, and March) and for the ARPEGE model in summer months (July, August, and September). The use of bias correction slightly decreases the area with statistically significant trends in summer months (June, July, and August) and slightly increases in the other months (Fig. 10). The largest differences are noted in September for DMI HIRHAM ARPEGE $(18.51 \%)$ and RM51 ARPEGE $(-11.92 \%)$, in February for KNMI RACMO2 ECHAM5 $(16.04 \%)$, in March for MPI M REMO ECHAM5 (16.04\%) and in August for DMI HIRHAM ARPEGE (12.01\%). In the other months the differences in the areas with statistically significant trend between raw and bias corrected data are smaller than $10 \%$.

In addition to changes in the area with a statistically significant trend for raw and corrected data also mean slope of trend is slightly altered. The magnitude of these small differences depends on a climate model and the month under consideration. The highest differences were estimated for the ARPEGE models as an effect of the highest biases of simulated data; therefore, the most intense bias correction is applied in that case. 

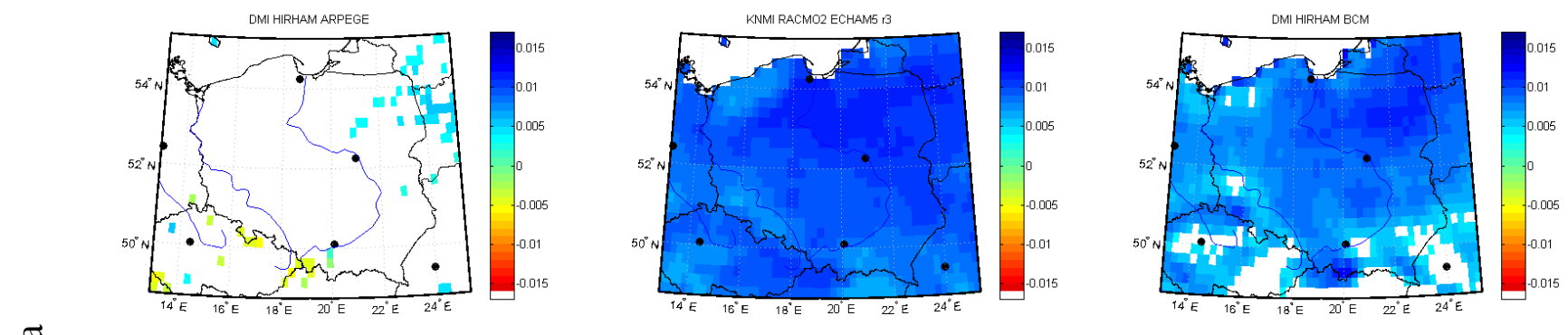

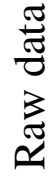
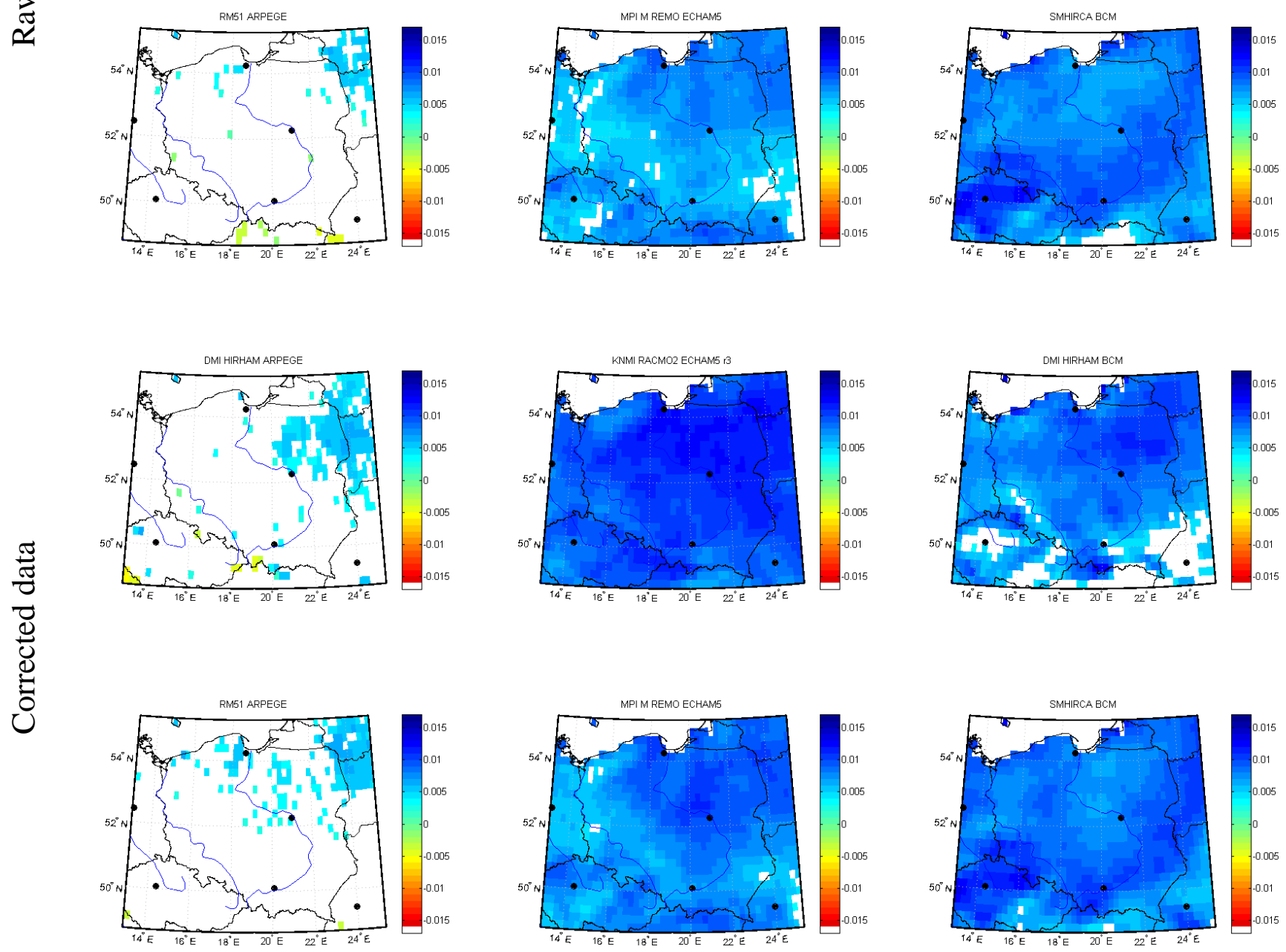

Figure 11. Results of the trend estimation using the Mann-Kendall method for the SPI 3 for the winter season (DJF). Colour scale denotes slope of the estimated trend. White colour denotes lack of statistically significant trends.

\subsubsection{SPI 3 and SPI 6}

In addition to the SPI 1, the SPI 3 for four seasons (DJF December, January, and February, MAM - March, April, and May, JJA - June, July, and August, SON - September, October and November) and the SPI 6 for two seasons, a cold one (November-April) and a warm one (May-October), are also analysed. The 12 maps presenting the slope of the trend for the SPI 3 for the winter season (DJF) are shown in Fig. 11. The outcomes for raw data presented in the upper part of Fig. 11 indicate that the results for ARPEGE differ from those for other climate models. According to that model, the estimated trends are not statistically significant for almost the whole of Poland. The other four models project an increase in the SPI 3 values. 

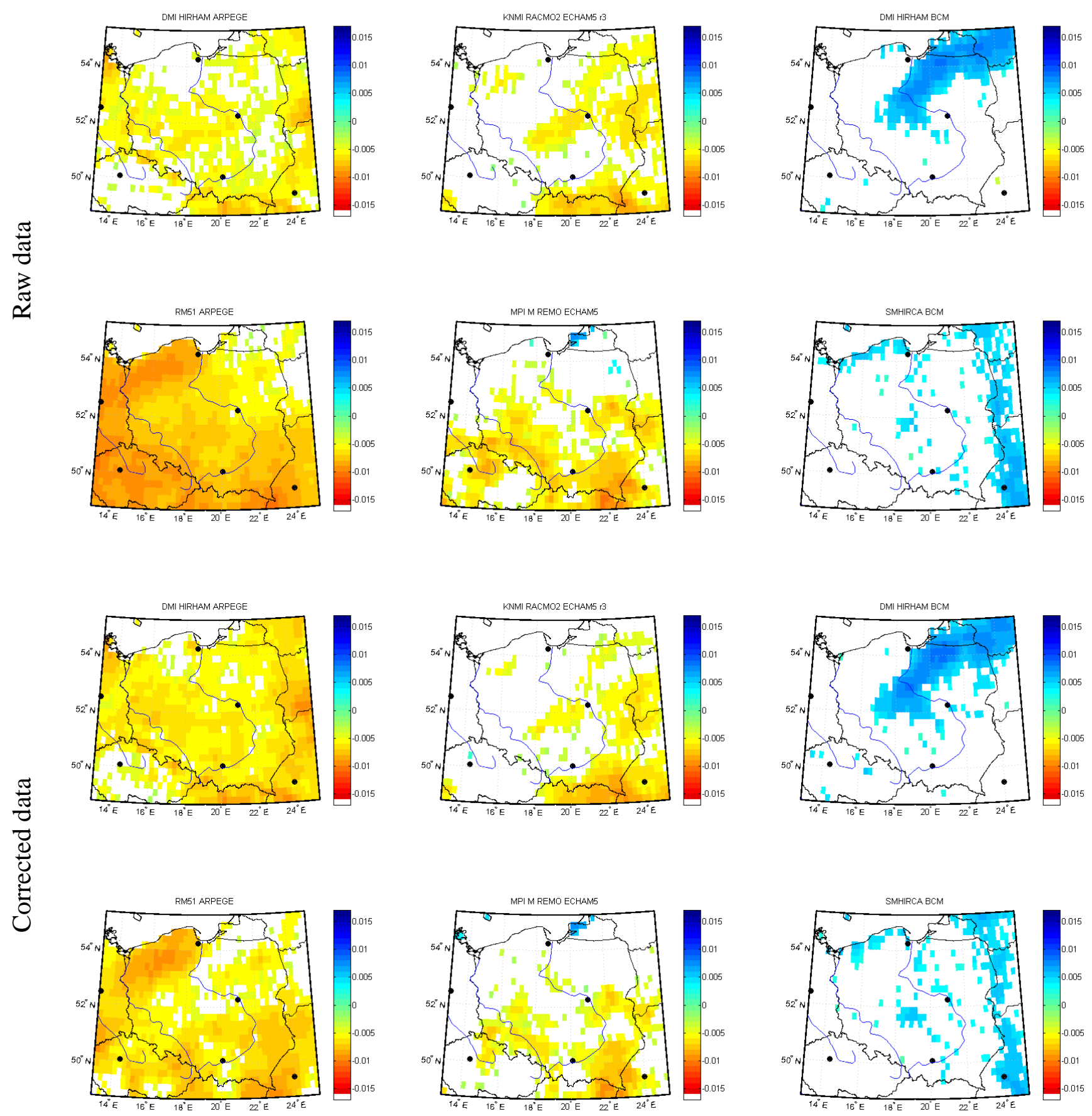

Figure 12. Trend for the SPI 3 for the summer period (JJA). The colour scale denotes the slope of the estimated trend. The white areas indicate the lack of a statistically significant trend.

The application of bias correction slightly alters the findings of the analysis. In that case the results resemble the latter for uncorrected data. The differences in the projections of climate models are preserved. As an effect of bias correction the number of grid cells with a statistically significant trend is slightly increasing for almost all climate models except DMI HIRHAM BCM. The slope of trend is also slightly higher for corrected data indicating more rapid changes.
The results of the analyses for the SPI 3 calculated for the summer season are presented in Fig. 12. The outcomes for uncorrected data in the upper part of figure indicate significant differences between the climate models. The simulations of the BCM global climate model project an increase in the SPI values in summer, corresponding to wetter conditions in the future. The other models simulate a decrease 
of the SPI, which is equivalent to an increase of a degree of dryness.

The slope of the trend for the corrected data is statistically significant for a larger area for three models: DMI HIRHAM ARPEGE, DMI HIRHAM BCM, and SMHIRCA BCM, and slightly lower for the RM51 ARPEGE and ECHAM5 models. The bias correction also influences the mean (over study area) magnitude of changes. In the case of DMI HIRHAM ARPEGE the mean slope of trend increases due to bias correction. Results for the other two models (MPI M REMO and RM51 ARPEGE) show an opposite tendency - an increase in the mean slope.

The results of the SPI 6 for the cold season (NovemberApril) are similar to those for the SPI 3 winter (Fig. S2). The application of the bias correction procedure slightly changes the outcomes obtained for the uncorrected data. There are still large differences in the tendency of the change between climate models.

For the warm period of the year (May-October), the estimated trends in the SPI 6 resemble those estimated for the summer months (JJA). The results are not similar between models. The ARPEGE GCM once again indicates an increase in the SPI values whilst the other climate models project a decrease. The application of bias correction leads to an increase in the area with statistically significant trends and the magnitude of the changes for DMI HIRHAM ARPEGE and corresponds to drier conditions. In the case of RM51 ARPEGE a decrease of number of grid cells with statistically significant trend and also its magnitude is achieved as a result of bias correction.

\subsubsection{SPI 12 and SPI 24}

The SPI was also estimated for longer timescales. The results for the annual scale (SPI 12, values extracted for precipitation totals over the calendar year, January-December) are shown in Fig. 13. The outcomes for the uncorrected data indicate differences between models. The ARPEGE model projects a decrease in the SPI values, whilst the other models show an increase in the SPI, corresponding to wetter conditions.

At the annual timescale the application of bias correction does not change the sign of the trend, but there are differences in the area affected and the magnitude of the changes. In the case of DMI HIRHAM ARPEGE and MPI M REMO ECHAM5, the correction of modelling biases leads to increases in the number of grid cells with a trend and also an increase in the magnitude of changes. On the other hand, the application of the bias correction procedure to RM51 ARPEGE model simulations leads to decreases in these factors.

The analysis of trends in the time series of the SPI 24 was also performed. Similarly to the outcomes for SPI 12, the estimated trends differ between the climate models. The results based on the ARPEGE model project a decrease in the SPI values (drier conditions). The other models indicate an increase in the SPI, corresponding to wetter conditions. The simulations of all global climate models (the ARPEGE, ECHAM5 and BCM) do not change the sign of the trend when bias correction is applied, but it makes a difference in the magnitude of the changes, leading to differences in the number of grid cells with statistically significant trend.

\subsection{Influence of bias correction on trend in precipitation and SPI values}

The results shown in the previous section indicate that the influence of bias correction on the trends is small in comparison with the variability between climate models. In order to explain the mechanism by which bias correction influences trends in precipitation, let us analyse a simple example of a linear dependence of precipitation on time, for one grid cell and 1 month:

$P^{\mathrm{RCM}}=\beta_{\mathrm{RCM}} t+\alpha_{\mathrm{RCM}}$,

where $\beta_{\mathrm{RCM}}$ and $\alpha_{\mathrm{RCM}}$ are coefficients of a linear trend.

After transformation using Eq. (3) we get

$P_{\mathrm{corr}}^{\mathrm{RCM}}=b\left(\beta_{\mathrm{RCM}} t+\alpha_{\mathrm{RCM}}-x_{0}\right)^{c}$.

Assuming $c=1$ (i.e. that the relationship can be approximated as linear in our case) the equation can be simplified to

$P_{\mathrm{corr}}^{\mathrm{RCM}}=b\left(\beta_{\mathrm{RCM}} t+\alpha_{\mathrm{RCM}}-x_{0}\right)=b \beta_{\mathrm{RCM}} t+b \alpha_{\mathrm{RCM}}-b x_{0}$

and the slope of corrected time series can then be estimated as

$\beta_{\text {corr }}=b \beta_{\mathrm{RCM}}$.

In the simplified case, the slope of corrected time series depends on the slope of uncorrected time series multiplied by the parameter $b$ of the transformation function. The values of parameter $b$ give the sign and magnitude of the biases. When $P^{\mathrm{RCM}}$ is higher than $P^{\mathrm{Obs}}$ the biases are positive and the values of parameter $b$ are smaller than 1 ; therefore, the slope of the trend of corrected time series is smaller than that for the uncorrected time series. In the opposite situation with negative biases (i.e. $P^{\mathrm{RCM}}<P^{\mathrm{Obs}}$ ), the values of parameter $b$ are higher than 1 , and as a result the corrected slope is higher than the uncorrected one.

In the case of precipitation time series, the values of these series are non-negative; therefore, the values of parameter $b$ (Eq. 3) are also non-negative. These considerations lead to the conclusion that the application of bias correction does not change the sign of estimated trend, but its slope may be changed. Due to changes in slope, the number of grid cells with a statistically significant trend in the sums of precipitation may also change. 

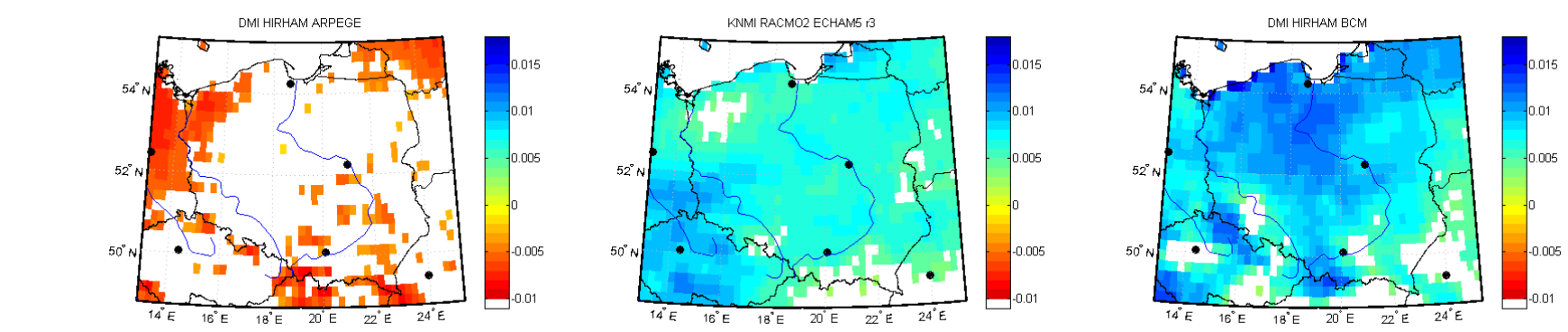

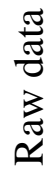
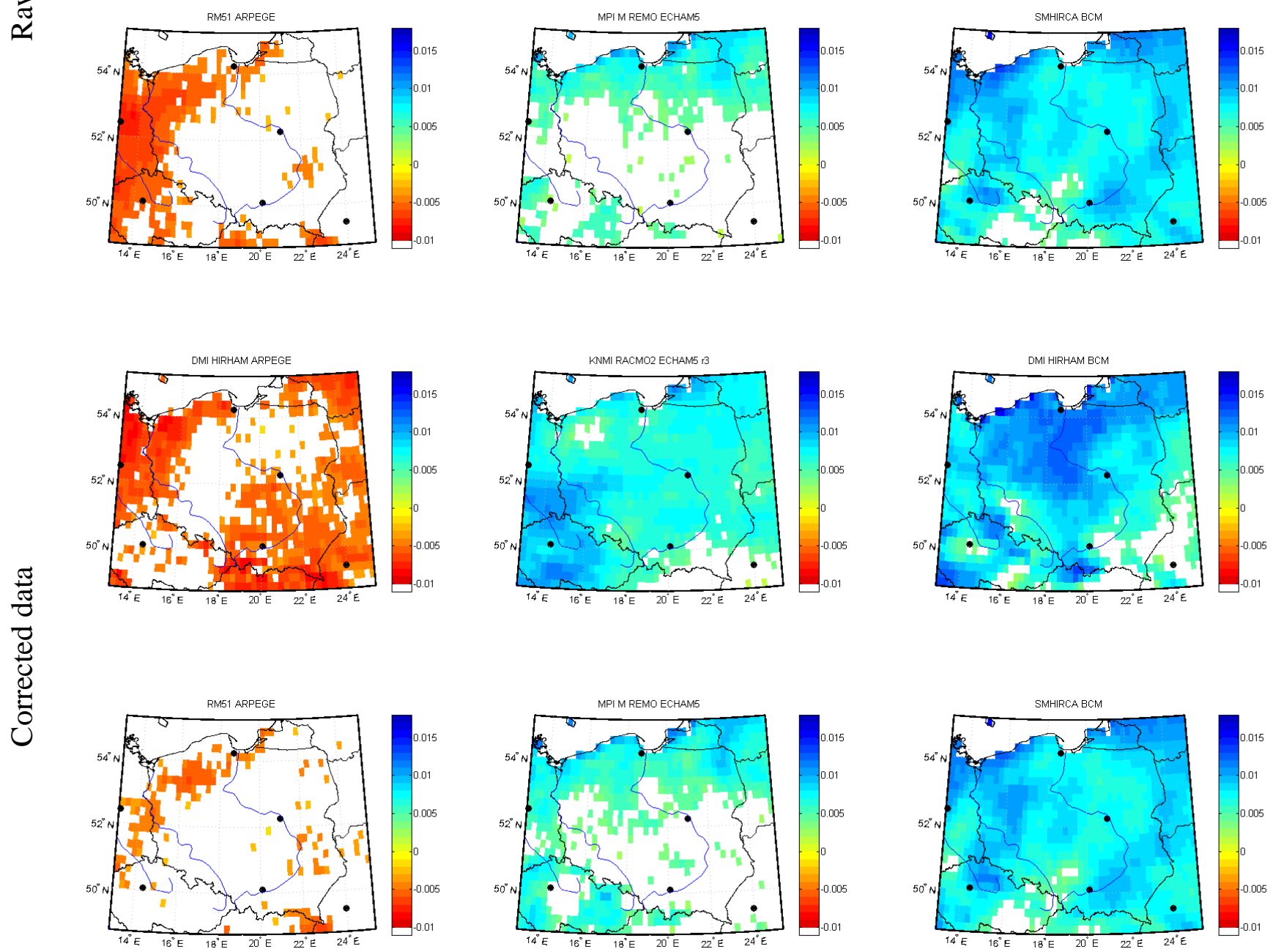

Figure 13. Trends in the SPI 12. Colour scale denotes the slope of the estimated linear trend. White areas indicate the lack of statistically significant trend.

The bias correction also influences the trends in the SPI values, however to a much smaller degree. The SPI is calculated by a non-linear transformation of the precipitation time series from a gamma distribution into a standard normal distribution. An example of such relationship between monthly sum of precipitation and SPI 1 values for DMI HIRHAM ARPEGE model simulations for one grid cell located close to Białystok is presented in Fig. 14. In each case (month) two such curves are presented. The red and black curves denote the relationship for uncorrected and corrected variables, respectively.

Figure 14 shows that quite large changes in precipitation are transformed into small changes in the SPI 1 values. The transformation is monotonic; hence, the direction of changes (trends) in precipitation is reflected in changes of SPI. However, due to the shape of the transformation these changes are 


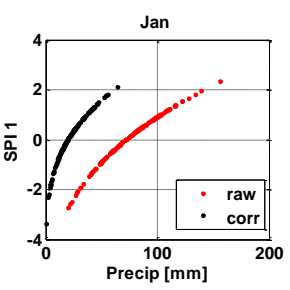

May
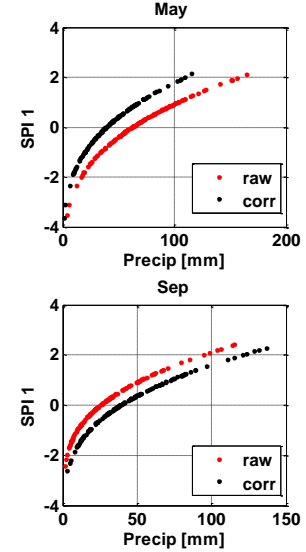

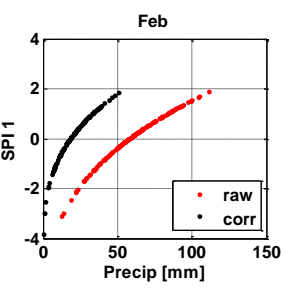

Jun

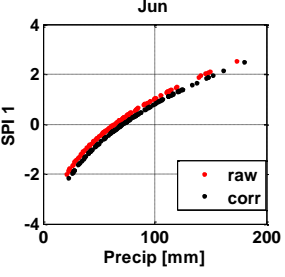

Oct

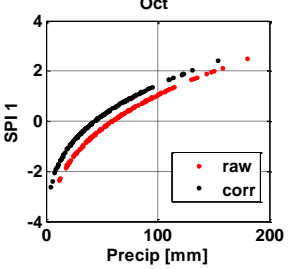

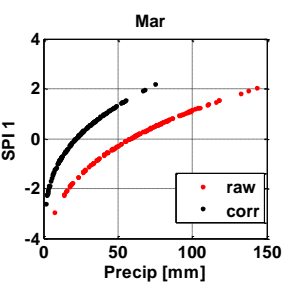
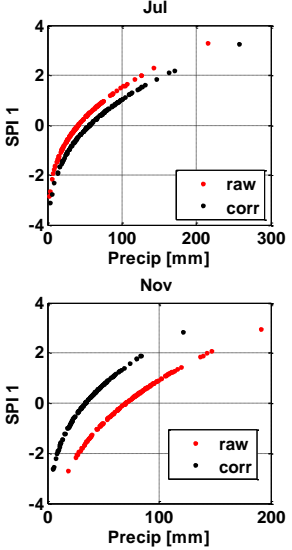

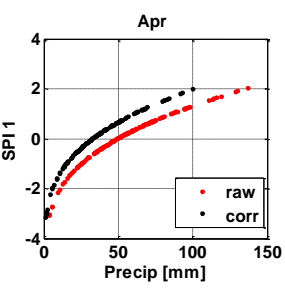

Aug
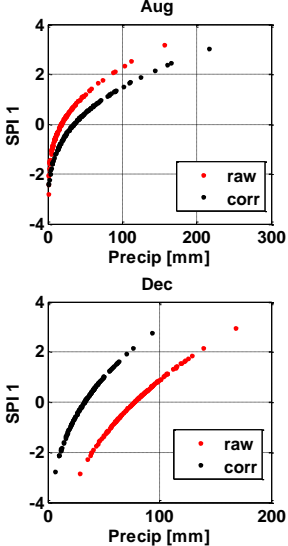

Figure 14. The scatter plots showing relationship between monthly sum of precipitation and estimated SPI 1 values for one grid cell located close to Białystok (NE Poland) for DMI HIRHAM ARPEGE model. The colour denotes type of data used, red colour - uncorrected precipitation and SPI 1, black corrected ones.

reduced. The dependence between the values of the SPI and precipitation shown in Fig. 14 for a specific model indicates that a simple relationship between the SPI values based on corrected and raw precipitation projections can be derived. In particular, under the assumption that bias correction is quasilinear and follows Eq. (3) with a power parameter $c=1$, the corrected SPI is linearly related to the SPI based on raw precipitation data with correlation parameters depending on the bias correction parameter $b$ (Eq. 3) and normalising transformation of precipitation sums into SPI values shown in Fig. 14.

In reality, additional factors have an effect on the SPI, including an uncertainty of distribution fitting applied in bias correction and the SPI calculation procedures. A test of differences between uncorrected and corrected SPI time series was performed using the Pearson correlation coefficient. The results of the correlation analysis for six climate models and 12 months for all grid cells are presented in Table 3. In all cases the correlation is statistically significant at the $5 \%$ level and the values of the minimum Pearson correlation coefficient are above 0.8 , indicating a nearly linear relationship between the indices. We also tested the dependence of relative differences in monthly precipitation on the correlation in the SPI values. The outcomes for all grid cells are presented in Fig. 15. A non-linear relationship is visible for most months and models that is statistically significant at $5 \%$ level, except for DMI HIRHAM ARPEGE and DMI HIRHAM BCM in June. The strength of these dependencies assessed using the Spearman correlation coefficient (SCC) varies from 0 up to 0.7954 with differences between months and models. The deviation from zero of the SCC values quantifies the influence of additional effects that include the non-linearity of the bias correction function and uncertainty in probability distribution of observed and simulated aggregated precipitation.

\section{Discussion and conclusions}

Potential future trends in the SPI index over the period 19712099 have been analysed using a modified Mann-Kendall test applied to precipitation time series derived from six ENSEMBLE RCM projections. Monthly precipitation timeseries have been used for the estimation of standardized precipitation index (SPI) for multiple timescales $(1,3,6,12$, and 24 months) at a spatial resolution of $25 \mathrm{~km}$ for the whole country. In the first stage, the simulated monthly sums of precipitation for the reference period (1971-2000) were compared with observed sums derived on the basis of the E-OBS reanalysis for the same period. We also compared those simulations with bias corrected precipitation time series. Results indicate that the uncorrected RCM time series overestimate precipitation values and that the annual pattern of monthly precipitation is not correctly reproduced. We also noticed large differences between results for various RCM-GCM combinations. The comparison of the simulated and observed number of wet days indicated that uncorrected RCM precipitation time series highly overestimate the total number of rainy days, as has been previously well established (Sunyer 

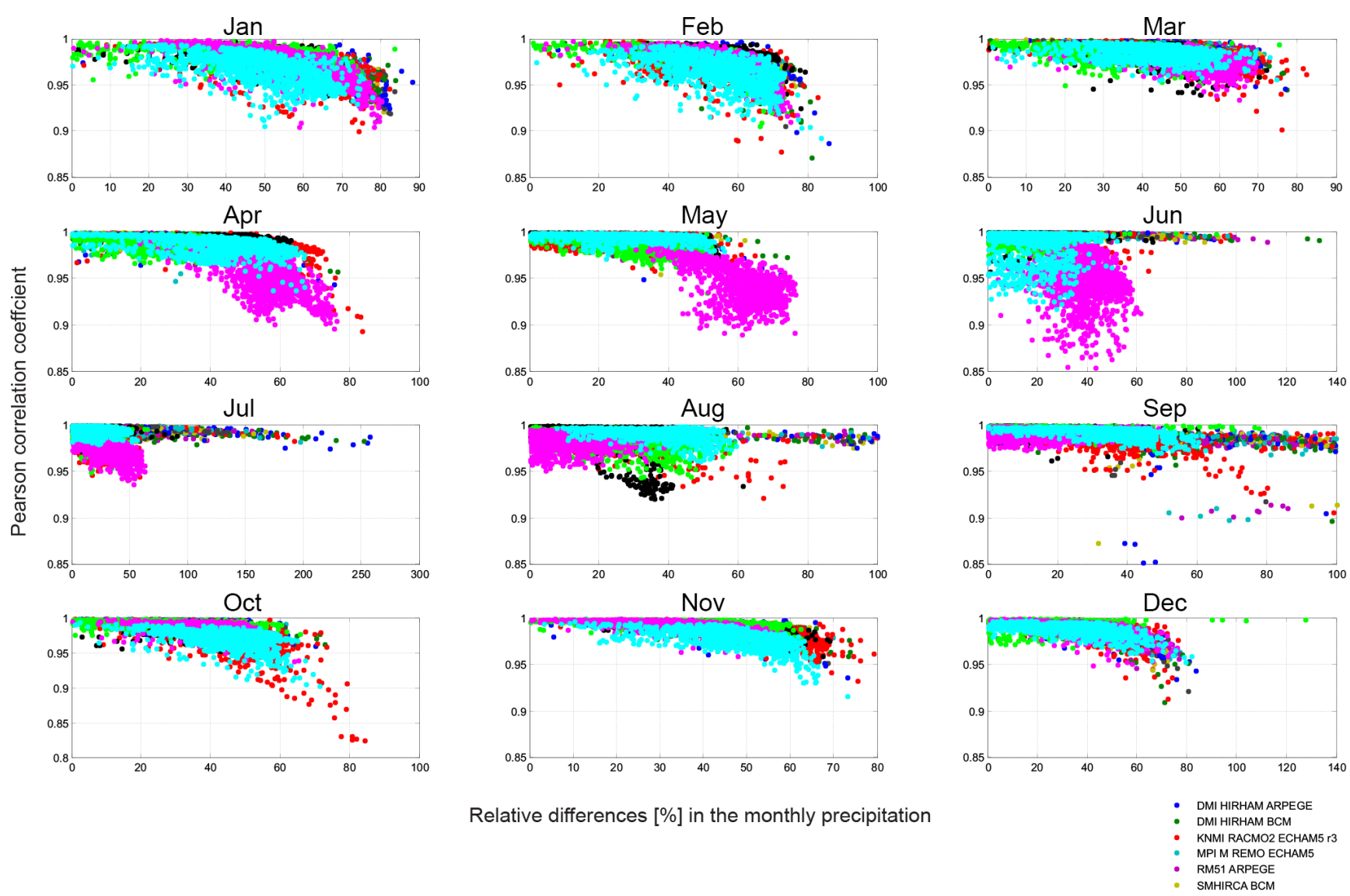

Figure 15. The scatter plots showing relationship between relative differences in the raw and corrected monthly sum of precipitation and Pearson correlation coefficient estimated for raw and corrected SPI 1 values for all grid cells.

et al., 2015). Application of bias correction using the quantile mapping method leads to improved precipitation values with respect to the seasonal pattern of precipitation, monthly total precipitation and the number of wet days, when compared with observed values.

For the estimation of trends in the SPI, we used a modified Mann-Kendall trend test for the SPI time series for each grid cell, each climate model and multiple temporal aggregations $(1,3,6,12$, and 24 months). The choice of this approach was dictated by its relative simplicity and robustness. Projections of SPI values indicate a decrease in the degree of dryness (better water availability) during the winter months and an increase in the summer period (more water scarcity) that confirm findings by Bleckinsop and Fowler (2007), Liszewska et al. (2012), Osuch et al. (2012), Rimkus et al. (2012), and Stagge et al. (2015b). The outcomes for longer timescales (SPI 12 and SPI 24) indicate an increasing trend in an ensemble SPI 12 (similarly to Orlowsky and Seneviratne, 2013) and considerable inter-model variability on regional and local scales. The ARPEGE GCM-driven RCM projections show a decrease of the SPI 12 and the SPI 24, whilst the other GCMdriven RCMs show an increase in the SPIs, corresponding to wetter conditions. These results confirm the general findings of Bleckinsop and Fowler (2007) showing considerable differences between climate model simulations. In general, our study also confirms the results of Stagge et al. (2015b) with some differences due to different climate models, emission scenarios and change estimation methods applied. In particular, our selection of climate models shows larger differences between climatic projections.

Our results indicate that the spatial pattern of the trend depends on the climate model, the temporal aggregation considered and, to some extent, whether or not bias correction is applied. Differences between the climate model projections were found to be larger than the discrepancies introduced by bias correction for all aggregation scales $(1,3,6,12$, and 24 months). These results contradict findings of Maurer and Pierce (2014) where uncertainty introduced by bias correction was found to be larger than the differences between climate models. This could reflect differences between the study areas, as precipitation projections for Poland are not consistent between the different climate models. We also noticed that results from the same GCM, but different RCMs, are characterized by similar patterns of change, although this behaviour occurs only at some temporal scales and seasons. 
Table 3. Estimated values of Pearson correlation coefficient between raw and corrected SPI time series for six climate models. A minimum value over all grid cells is shown.

\begin{tabular}{|c|c|c|c|c|c|c|c|}
\hline \multirow[t]{2}{*}{ Index } & \multirow{2}{*}{$\begin{array}{l}\text { GCM } \\
\text { RCM }\end{array}$} & \multicolumn{2}{|c|}{ ARPEGE } & \multicolumn{2}{|c|}{ ECHAM5 } & \multicolumn{2}{|c|}{$\mathrm{BCM}$} \\
\hline & & $\begin{array}{c}\text { DMI } \\
\text { HIRHAM }\end{array}$ & RM51 & $\begin{array}{l}\text { MPI M } \\
\text { REMO }\end{array}$ & $\begin{array}{c}\text { KNMI } \\
\text { RACMO2 }\end{array}$ & $\begin{array}{c}\text { DMI } \\
\text { HIRHAM }\end{array}$ & SMHIRCA \\
\hline \multirow{12}{*}{ SPI 1} & Jan & 0.9002 & 0.9043 & 0.9434 & 0.9391 & 0.9134 & 0.9059 \\
\hline & Feb & 0.8718 & 0.9104 & 0.9055 & 0.9252 & 0.8783 & 0.8932 \\
\hline & Mar & 0.9452 & 0.9341 & 0.9502 & 0.9396 & 0.9018 & 0.9551 \\
\hline & Apr & 0.9436 & 0.8964 & 0.9638 & 0.9589 & 0.8939 & 0.9374 \\
\hline & May & 0.9490 & 0.8897 & 0.9343 & 0.9680 & 0.9568 & 0.9711 \\
\hline & Jun & 0.9738 & 0.8544 & 0.9440 & 0.9573 & 0.9582 & 0.9173 \\
\hline & Jul & 0.9749 & 0.9368 & 0.9488 & 0.9698 & 0.9415 & 0.9798 \\
\hline & Aug & 0.8200 & 0.9513 & 0.9436 & 0.9207 & 0.9217 & 0.9614 \\
\hline & Sep & 0.8064 & 0.9730 & 0.9728 & 0.9619 & 0.9260 & 0.9702 \\
\hline & Oct & 0.9601 & 0.9386 & 0.9666 & 0.9529 & 0.8253 & 0.9028 \\
\hline & Nov & 0.9364 & 0.9592 & 0.9619 & 0.9591 & 0.9332 & 0.9161 \\
\hline & Dec & 0.9103 & 0.9492 & 0.9687 & 0.9721 & 0.9138 & 0.9532 \\
\hline \multirow{4}{*}{ SPI 3} & DJF & 0.8679 & 0.9344 & 0.9580 & 0.9588 & 0.9215 & 0.9157 \\
\hline & MAM & 0.9171 & 0.8450 & 0.9544 & 0.9542 & 0.9187 & 0.9604 \\
\hline & JJA & 0.9376 & 0.9105 & 0.9436 & 0.9664 & 0.9224 & 0.9592 \\
\hline & SON & 0.8758 & 0.9429 & 0.9462 & 0.9508 & 0.8788 & 0.9134 \\
\hline \multirow{2}{*}{ SPI 6} & Nov-Apr & 0.9014 & 0.9348 & 0.9534 & 0.9660 & 0.9214 & 0.9220 \\
\hline & May-Oct & 0.9077 & 0.9077 & 0.9369 & 0.9659 & 0.8874 & 0.9626 \\
\hline SPI 12 & $\begin{array}{l}\text { Calendar } \\
\text { year }\end{array}$ & 0.8522 & 0.8840 & 0.9450 & 0.9514 & 0.8680 & 0.9360 \\
\hline SPI 24 & $\begin{array}{l}\text { Two } \\
\text { calendar } \\
\text { years }\end{array}$ & 0.8651 & 0.9029 & 0.9411 & 0.9479 & 0.8450 & 0.9137 \\
\hline
\end{tabular}

An analysis of the impact of bias correction on the trends in SPI values was carried out in two steps: (i) an assessment of the effects of bias correction on the trend of aggregated precipitation and (ii) an assessment of the effect of that trend on the SPI values. The results of the analysis indicate that bias correction may change the magnitude of the trend in precipitation values but not its direction. These changes vary throughout the year and between climate models, but spatial patterns showing areas with a statistically significant trend are preserved. These findings are confirmed by a theoretical investigation of the influence of bias correction on trends in precipitation using a simple example of a linear bias correction procedure. In that case the slope of the trend of the corrected precipitation time series is influenced by the parameters of the power relationship between uncorrected and corrected precipitation values in the reference period.

Where the SPI values are concerned, the influence of the bias correction has a similar character but are much reduced in comparison with precipitation due to the normalization procedure included in both the bias correction and the SPI definition. The analysis of correlation between the SPI values based on corrected and uncorrected precipitation indicates a nearly one-to-one relationship between them. However, that correlation decreases when the relative differences between corrected and uncorrected precipitation increase.

The differences between SPI values for bias-corrected and raw precipitation projections depend on the month and climate model. Those monthly differences are consistent with the bias correction parameters (Eq. 3). The largest differences occur for months when the bias correction is the strongest. In reality, additional factors have an effect on the trends in the SPI that include the non-linearity of the bias correction function and uncertainty in the probability distribution of observed and simulated precipitation totals. Further analyses of an influence of bias correction on trends in hydrometeorological variables are recommended.

\section{The Supplement related to this article is available online at doi:10.5194/hess-20-1947-2016-supplement.}

Acknowledgements. The work was undertaken within the project "Climate Change Impacts on Hydrological Extremes (CHIHE)" Pol-Nor/196243/80/2013, which is supported by the NorwayPoland Grants Program administered by the Norwegian Research 
Council. The RCM-GCM projections were obtained from the EU FP6 ENSEMBLES project.

Edited by: J. Hannaford

\section{References}

Agnew, C. T.: Using the SPI to Identify Drought, Drought Network News (1994-2001), Paper 1, National Drought Mitigation Center, University of Nebraska, Lincoln, 6-12, 2000.

Alexander, L. V., Zhang, X., Peterson, T. C., Caesar, J., Gleason, B., Klein Tank, A. M. G., Haylock, M., Collins, D., Trewin, B., Rahimzadeh, F., Tagipour, A., Kumar, K. R., Revadekar, J., Griffiths, G., Vincent, L., Stephenson, D. B., Burn, J., Aguilar, E., Brunet, M., Taylor, M., New, M., Zhai, P., Rusticucci, M., and Vazquez-Aguirre, J. L.: Global observed changes in daily climate extremes of temperature and precipitation, J. Geophys. Res.-Atmos., 111, D05109, doi:10.1029/2005JD006290, 2006.

Bartholy, J. and Pongracz, R.: Regional analysis of extreme temperature and precipitation indices for the Carpathian Basin from 1946 to 2001, Global Planet. Change, 57, 83-95, 2007.

Blenkinsop, S. and Fowler, H. J.: Changes in European drought characteristics projected by the PRUDENCE regional climate models, Int. J. Climatol., 27, 1595-1610, 2007.

Bordi, I., Fraedrich, K., and Sutera, A.: Observed drought and wetness trends in Europe: an update, Hydrol. Earth Syst. Sci., 13, 1519-1530, doi:10.5194/hess-13-1519-2009, 2009.

Brázdil, R., Trnka, M., Dobrovolny, P., Chromi, K., Hlavinka, P., and Zalud, Z.: Variability of droughts in the Czech Republic, 1881-2006, Theor. Appl. Climatol., 97, 297-315, 2009.

Christensen, J. H., Boberg, F., Christensen, O. B., and LucasPicher, P.: On the need for bias correction of regional climate change projections of temperature and precipitation, Geophys. Res. Lett., 35, L20709, doi:10.1029/2008GL035694, 2008.

Cloke, H. L., Wetterhall, F., He, Y., Freer, J. E., and Pappenberger, F.: Modelling climate impact on floods with ensemble climate projections, Q. J. R. Meteorol. Soc., 139, 282-297, 2013.

Dai, A.: Drought under global warming: a review, Wiley Interdisciplinary Reviews: Climate Change, 2, 45-65, 2011.

Dosio, A. and Paruolo, P.: Bias correction of the ENSEMBLES high-resolution climate change projections for use by impact models: Evaluation on the present climate, J. Geophys. Res., 116, D16106, doi:10.1029/2011JD015934, 2011.

Dutra, E., Wetterhall, F., Di Giuseppe, F., Naumann, G., Barbosa, P., Vogt, J., Pozzi, W., and Pappenberger, F.: Global meteorological drought - Part 1: Probabilistic monitoring, Hydrol. Earth Syst. Sci., 18, 2657-2667, doi:10.5194/hess-18-2657-2014, 2014.

Ehret, U., Zehe, E., Wulfmeyer, V., Warrach-Sagi, K., and Liebert, J.: HESS Opinions "Should we apply bias correction to global and regional climate model data?", Hydrol. Earth Syst. Sci., 16, 3391-3404, doi:10.5194/hess-16-3391-2012, 2012.

Fischer, T, Gemmer, M., Su, B., and Scholten, T.: Hydrological long-term dry and wet periods in the Xijiang River basin, South China, Hydrol. Earth Syst. Sci., 17, 135-148, doi:10.5194/hess17-135-2013, 2013.

Gocic, M. and Trajkovic, S.: Analysis of precipitation and drought data in Serbia over the period 1980-2010, J. Hydrol., 494, 32-42, 2013.
Gudmundsson, L., Bremnes, J. B., Haugen, J. E., and EngenSkaugen, T.: Technical Note: Downscaling RCM precipitation to the station scale using statistical transformations - a comparison of methods, Hydrol. Earth Syst. Sci., 16, 3383-3390, doi:10.5194/hess-16-3383-2012, 2012.

Gutjahr, O. and Heinemann, G.: Comparing precipitation bias correction methods for high-resolution regional climate simulations using COSMO-CLM, Theor. Appl. Climatol., 114, 511-529, doi:10.1007/s00704-013-0834-z, 2013.

Hagemann, S., Chen, C., Haerter, J. O., Heinke, J., Gerten, D., and Piani, C.: Impact of a statistical bias correction on the projected hydrological changes obtained from three GCMs and two hydrology models, J. Hydrometeorol., 12, 556-578, doi:10.1175/2011jhm1336.1, 2011.

Hamed, K. H. and Rao, A. R.: A modified Mann-Kendall trend test for autocorrelated data, J. Hydrol., 204, 182-196, 1998.

Hayes, M., Svoboda, M. D., Wilhite, D. A., and Vayarkho, O. V.: Monitoring the 1996 drought using the Standardized Precipitation Index, B. Am. Meteorol. Soc., 80, 429-438, 1999.

Haylock, M. R., Hofstra, N., Klein Tank, A. M. G., Klok, E. J., Jones, P. D., and New, M.: A European daily highresolution gridded data set of surface temperature and precipitation for 1950-2006, J. Geophys. Res., 113, D20119, doi:10.1029/2008JD010201, 2008.

IPCC: Managing the Risks of Extreme Events and Disasters to Advance Climate Change Adaptation, in: A Special Report of Working Groups I and II of the Intergovernmental Panel on Climate Change, edited by: Field, C. B., Barros, V., Stocker, T. F., Qin, D., Dokken, D. J., Ebi, K. L., Mastrandrea, M. D., Mach, K. J., Plattner, G.-K., Allen, S. K., Tignor, M., and Midgley, P. M., Cambridge University Press, Cambridge, UK, and New York, NY, USA, 582 pp., 2012.

IPCC: Climate Change 2014: Impacts, Adaptation, and Vulnerability, Part A: Global and Sectoral Aspects, in: Contribution of Working Group II to the Fifth Assessment Report of the Intergovernmental Panel on Climate Change, edited by: Field, C. B., Barros, V. R., Dokken, D. J., Mach, K. J., Mastrandrea, M. D., Bilir, T. E., Chatterjee, M., Ebi, K. L., Estrada, Y. O., Genova, R. C., Girma, B., Kissel, E. S., Levy, A. N., MacCracken, S., Mastrandrea, P. R., and White, L. L., Cambridge University Press, Cambridge, UK and New York, NY, USA, 1132 pp., 2014.

Jenkins, K. and Warren, R.: Quantifying the impact of climate change on drought regimes using the Standardised Precipitation Index, Theor. Appl. Climatol., 120, 41-54, 2015.

Kaczmarek, Z., Strzepek, K. M., Somlyody, L., and Priazhinskaya, V.: Water Resources Management in the Face of Climatic/Hydrologic Uncertainties, Water science and technology library v.18, Kluwer Academic Publishers, Dordrecht, the Netherlands, 395 pp., 1996.

Kendall, M. G.: Rank Correlation Methods, 4th Edn., Charles Griffin, London, 272 pp., 1975.

Kiktev, D. M., Caesar, J., and Alexander, L.: Temperature and precipitation extremes in the second half of the twentieth century from numerical modelling results and observational data, Izvest. Atmos. Ocean. Phys., 45, 284-293, 2009.

KLIMADA: Development and implementation of the Polish National Strategy for Adaptation to Climate Change - KLIMADA, http://klimada.mos.gov.pl/en/climate-change-in-poland/ (last access: 10 May 2016), 2012. 
Knutti, R., Furrer, R., Tebaldi, C., Cermak, J., and Meehl, G.: Challenges in Combining Projections from Multiple Climate Models, J. Climate, 23, 2739-2758, doi:10.1175/2009JCLI3361.1, 2010.

Kumar, M. N., Murthy, C. S., Sesha Sai, M. V. R., and Roy, P. S.: On the use of Standardized Precipitation Index (SPI) for drought intensity assessment, Meteorol. Appl., 16, 381-389, doi:10.1002/met.136, 2009.

Kundzewicz, Z. W. and Robson, A. J.: Change detection in hydrological records - a review of the methodology, Hydrolog. Sci. J., 49, 7-19, 2004.

Łabędzki, L.: Estimation of local drought frequency in Central Poland using the standarized precipitation index SPI, Irrig. Drain., 56, 67-77, 2007.

Łabędzki, L. and Bąk, B.: Meteorological and agricultural drought indices used in drought monitoring in Poland: a review, Meteorol. Hydrol. Water Manage. Res. Oper. Appl.s, 2, 3-13, 2014.

Łabędzki, L. and Kanecka-Geszke E.: Standardized evapotranspiration as an agricultural drought index, Irrig. Drain., 58, 607-616, 2009.

Liszewska, M., Konca-Kędzierska, K., Jakubiak, B., and Śmiałecka, E.: Opracowanie scenariuszy zmian klimatu dla Polski i wybranych regionów, Report 2, KLIMADA project, ICM, Warsaw, 54 pp., 2012.

Liu, L., Hong, Y., Looper, J., Riley, R., Yong, B., Zhang, Z., Hocker, J., and Shafer, M.: Climatological Drought Analyses and Projection Using SPI and PDSI: Case Study of the Arkansas Red River Basin, J. Hydrol. Eng., 18, 809-816, 2013.

Lloyd-Hughes, B. and Saunders, M. A.: A drought climatology for Europe, Int. J. Climatol., 22, 1571-1592, 2002.

Madsen, H., Lawrence, D., Lang, M., Martinkova, M., and Kjeldsen, T. R.: Review of trend analysis and climate change projections of extreme precipitation and floods in Europe, J. Hydrol., 519, 3634-3650, 2014.

Mann, H. B.: Non-parametric tests against trend, Econometrica, 13, 163-171, 1945.

Maurer, E. P. and Pierce, D. W.: Bias correction can modify climate model simulated precipitation changes without adverse effect on the ensemble mean, Hydrol. Earth Syst. Sci., 18, 915925, doi:10.5194/hess-18-915-2014, 2014.

McKee, T. B., Doeskin, N. J., and Kleist, J.: The relationship of drought frequency and duration to time scales, in: Proceedings of the 8th Conference on Applied Climatology, 17-22 January 1993, Anaheim, CA, 179-184, 1993.

Mishra, A. K. and Singh, V. P.: A review of drought concepts, J. Hydrol., 391, 202-216, 2010.

Moreira, E. E., Mexia, J. T., and Pereira, L. S.: Are drought occurrence and severity aggravating? A study on SPI drought class transitions using log-linear models and ANOVA-like inference, Hydrol. Earth Syst. Sci., 16, 3011-3028, doi:10.5194/hess-163011-2012, 2012.

Muerth, M. J., Gauvin St-Denis, B., Ricard, S., Velázquez, J. A., Schmid, J., Minville, M., Caya, D., Chaumont, D., Ludwig, R., and Turcotte, R.: On the need for bias correction in regional climate scenarios to assess climate change impacts on river runoff, Hydrol. Earth Syst. Sci., 17, 1189-1204, doi:10.5194/hess-171189-2013, 2013.

Nakicenovic, N., Alcamo, J., Davis, G., Fenhann, J., Gaffin, S., Gregory, K., Grübler, A., Jung, T. Y., Kram, T., La Rovere, E. L., Michaelis, L., Mori, S., Morita, T., Pepper, W., Pitscher, H.,
Price, L., Raihi, K., Roehrl, A., Rogner, H.-H., Sankovski, A., Schlesinger, M., Shukla, P., Smith, S., Swart, R., can Rooijen, S., Victor, N., de Vries, B., and Dadi, Z.: Emissions Scenarios, in: A Special Report of Working Group III of the Intergovernmental Panel on Climate Change, Cambridge University Press, Cambridge, UK and New York, NY, USA, 599 pp., 2000.

NAS: Polish National Strategy for Adaptation to Climate Change (NAS 2020) with the perspective by 2030, Ministry of the Environment Republic of Poland, Warsaw, https://klimada.mos. gov.pl/wp-content/uploads/2014/12/ENG_SPA2020_final.pdf (last access: 10 May 2016), 2013.

Orlowsky, B. and Seneviratne, S. I.: Elusive drought: uncertainty in observed trends and short- and long-term CMIP5 projections, Hydrol. Earth Syst. Sci., 17, 1765-1781, doi:10.5194/hess-171765-2013, 2013.

Osuch, M., Kindler, J., Romanowicz, R. J., Berbeka, K., and Banrowska, A.: KLIMADA Strategia adaptacji Polski do zmian klimatu w zakresie sektora "Zasoby i gospodarka wodna". KLIMADA project, IGF PAN, Warsaw, 245 pp., 2012.

Piani, C., Haerter, J. O., and Coppola, E.: Statistical bias correction for daily precipitation in regional climate models over Europe, Theor. Appl. Climatol., 99, 187-192, 2010.

Rimkus, E., Valiukas, D., Kazys, J., Gecaite, I., and Stonevicius, E.: Dryness dynamics of the Baltic Sea region, Baltica, 25, 129-142, 2012.

Seiler, R. A., Hayes, M., and Bressan, L.: Using the Standardized Precipitation Index for flood risk monitoring, Int. J. Climatol., 22, 1365-1376, 2002.

Seneviratne, S. I., Nicholls, N., Easterling, D., Goodess, C. M., Kanae, S., Kossin, J., Luo, Y., Marengo, J., McInnes, K., Rahimi, M., Reichstein, M., Sorteberg, A., Vera, C., and Zhang, X.: Changes in climate extremes and their impacts on the natural physical environment, in: Managing the Risks of Extreme Events and Disasters to Advance Climate Change Adaptation, A Special Report of Working Groups I and II of the Intergovernmental Panel on Climate Change (IPCC), edited by: Field, C. B., Barros, V., Stocker, T. F., Qin, D., Dokken, D. J., Ebi, K. L., Mastrandrea, M. D., Mach, K. J., Plattner, G.-K., Allen, S. K., Tignor, M., and Midgley, P. M., Cambridge University Press, Cambridge, UK, and New York, NY, USA, 109-230, 2012.

Sienz, F., Bothe, O., and Fraedrich, K.: Monitoring and quantifying future climate projections of dryness and wetness extremes: SPI bias, Hydrol. Earth Syst. Sci., 16, 2143-2157, doi:10.5194/hess16-2143-2012, 2012.

Somorowska, U.: Increase in the hydrological drought risk in different geographical regions of Poland in the $20^{\text {th }}$ century, Prace $i$ Studia Geograficzne, 43, 97-114, 2009.

Stagge, J. H., Tallaksen, L. M., Gudmundsson, L., Van Loon, A. F., and Stahl, K.: Candidate Distributions for Climatological Drought Indices (SPI and SPEI), Int. J. Climatol., 35, 40274040, doi:10.1002/joc.4267, 2015a.

Stagge, J. H., Rizzi, J., Tallaksen, L. M., and Stahl, K.: Future meteorological drought: projections of regional climate models for Europe, Technical Report No. 25, Future Meteorological Drought Projections of Regional Climate, DROUGHT-RSPI Project, University of Oslo, Oslo, 23 pp., 2015 b.

Sunyer, M. A., Hundecha, Y., Lawrence, D., Madsen, H., Willems, P., Martinkova, M., Vormoor, K., Bürger, G., Hanel, M., Kriaučiūnienè, J., Loukas, A., Osuch, M., and Yücel, I.: Inter- 
comparison of statistical downscaling methods for projection of extreme precipitation in Europe, Hydrol. Earth Syst. Sci., 19, 1827-1847, doi:10.5194/hess-19-1827-2015, 2015.

Swain, S. and Hayhoe, K.: CMIP5 projected changes in spring and summer drought and wet conditions over North America, Clim. Dynam., 44, 2737-2750, 2015.

Teng, J., Potter, N. J., Chiew, F. H. S., Zhang, L., Wang, B., Vaze, J., and Evans, J. P.: How does bias correction of regional climate model precipitation affect modelled runoff?, Hydrol. Earth Syst. Sci., 19, 711-728, doi:10.5194/hess-19-711-2015, 2015.

Teutschbein, C. and Seibert, J.: Is bias correction of regional climate model (RCM) simulations possible for nonstationary conditions?, Hydrol. Earth Syst. Sci., 17, 5061-5077, doi:10.5194/hess-17-5061-2013, 2013.

Tokarczyk, T.: Classification of low flow and hydrological drought for a river basin, Acta Geophys., 61, 404-421, 2013.

Tokarczyk, T. and Szalińska, W.: The operational drought hazard assessment scheme - performance and preliminary results, Arch. Environ. Prot., 39, 61-77, 2013.

Tokarczyk, T, and Szalińska, W.: Combined analysis of precipitation and water deficit for drought hazard assessment, Hydrolog. Sci. J., 59, 1675-1689, 2014.

van der Linden, P. and Mitchell, J. F. B. (Eds.): ENSEMBLES: Climate Change and its Impacts: Summary of research and results from the ENSEMBLES project, technical report available at: http://ensembles-eu.metoffice.com/docs/ Ensembles_final_report_Nov09.pdf, last access: 3 June 2014, Met Office Hadley Centre, UK, 160 pp., 2009.
Vormoor, K., Lawrence, D., Heistermann, M., and Bronstert, A.: Climate change impacts on the seasonality and generation processes of floods - projections and uncertainties for catchments with mixed snowmelt/rainfall regimes, Hydrol. Earth Syst. Sci., 19, 913-931, doi:10.5194/hess-19-913-2015, 2015.

Wilcox, R. R.: Theil-Sen Estimator, in: Introduction to Robust Estimation and Hypothesis Testing, Academic Press, Amsterdam, the Netherlands, 423-427, 2005.

Wu, H., Hayes, M. J., Wilhite, D. A., and Svoboda, M. D.: The effect of the length of record on the standardized precipitation index calculation, Int. J. Climatol., 25, 505-520, 2005.

Wu, H., Svoboda, M. D., Hayes, M. J., Wilhite, D. A., and Wen, F. Appropriate application of the standardized precipitation index in arid locations and dry seasons, Int. J. Climatol., 27, 65-79, 2007.

Zarch, M. A. A., Sivakumar, B., and Sharma, A.: Droughts in a warming climate: A global assessment of Standardized precipitation index (SPI) and Reconnaissance drought index (RDI), J. Hydrol., 526, 183-195, 2015.

Zargar, A., Sadiq, R., and Khan, F. I.: Uncertainty-driven characterization of climate change effects on drought frequency using enhanced SPI, Water Resour. Manage., 28, 15-40, 2014. 